Article

\title{
From 0D to 3D thermo-fluid simulations of a Fan Outlet Guide Vane Cooler (FOGVC)
}

\author{
Luis Costero Sánchez ${ }^{1, *}$, Sagar Sadananda Bhat and Klaus Höschler ${ }^{1}$ \\ 1 Chair of Aeroengine Design, Brandenburg University of Technology Cottbus-Senftenberg, 03046 Cottbus, \\ Germany; fg-flug-triebwerksdesign@b-tu.de \\ * Correspondence: luiscssz@hotmail.com
}

\begin{abstract}
As the first time, 0D-1D-3D and fully 3D steady-state aero-thermo-fluid simulations of a structural oil-to-air Fan Outlet Guide Vane Cooler (FOGVC) in a jet engine are presented. Using the commercial softwares Ansys Fluent ${ }^{\mathrm{TM}}$, the thermo-mechanical module of Ansys ${ }^{\mathrm{TM}}$ and the 1D fluid solver Flownex ${ }^{\mathrm{TM}}, 5$ simulation types (3D fully conjugate heat transfer with and without a thin wall model, 3D with a thin wall model, 1D-3D coupled, 1D and 0D) corresponding to 4 levels of simplification in 3 possible domains (oil, oil-metal and oil-metal-air) have been compared to provide selection criteria when a determined level of accuracy in the simulations without prohibited computational times is desired. The methodologies are applied to two different oil internal cavities: an inverted $U$ with rectangular cross section and a coil internal cavity with a circular cross section. The obtained results show that depending on the scope of the research (outlet oil temperature, dissipated heat rate or oil pressure drop) and the accuracy of the results, one method or the other may be used. Experimental data would be needed to validate the numerical results by all employed methodologies and geometries.
\end{abstract}

Keywords: Fan Outlet Guide Vane Cooler (FOGVC); conjugate heat transfer (CHT); multiphysic; Ansys Fluent; ANSYS thermal (APDL); FLUID 116 thermal element; Flownex.

\section{Introduction}

To fulfill the EU climate goals by cutting greenhouse gas emissions by at least $55 \%$ by 2030 and become climate neutral by 2050 [1], the optimization of jet engines is essential. The new generation of jet engines with Ultra High Bypass Ratio (UHBPR), like the UltraFan ${ }^{\mathrm{TM}}$ [2], and European research programs, like Horizon 2020 [3] and Horizon Europe [4], make it possible to realise these goals by enhancing the heat management and reducing the weight. Key components in this optimization are lightweight heat exchangers, which dissipate generated heat in certain locations of the jet engine, e.g. in the by-pass duct with the Surface Air Cooled Oil Cooler (SACOC) or make possible the transport of part of this heat to take advantage of it somewhere else (anti-icing, decongealing,...). However the locations to mount new heat exchangers in a jet engine are quite limited. A possible strategy to overcome it, is the integration of heat exchangers in present jet engine components originally conceived for other tasks scattered on different components. A Fan Outlet Guide Vane (FOGV) or a Structured Guide Vane (SGV), another name for the FOGV, is a possible candidate for this integration. A FOGV, is a stator located after the fan in the by-pass duct and normally made of titanium. Its main mission is to remove the swirl coming from the fan and connect structurally the core engine with the fan cases, figure 1 .

The current tendency in the jet engine architecture design is to integrate new capabilities in the FOGVs, e.g. structural by removing structural components (frames) downstream of the FOGV, and thermal, using the FOGVs as heat exchangers (FOGVC), ([6], [7], [8], [9], [10], [11], [12], [13]). Due to the high heat dissipation surface available (around 40 FOGVs may belong to the FOGV assembly) and the continuous air flow in the by-pass duct, the FOGVs are perfect candidates to integrate the new thermal capabilities. The increase of the structural loads and a possible oil leak, e.g. in an event 


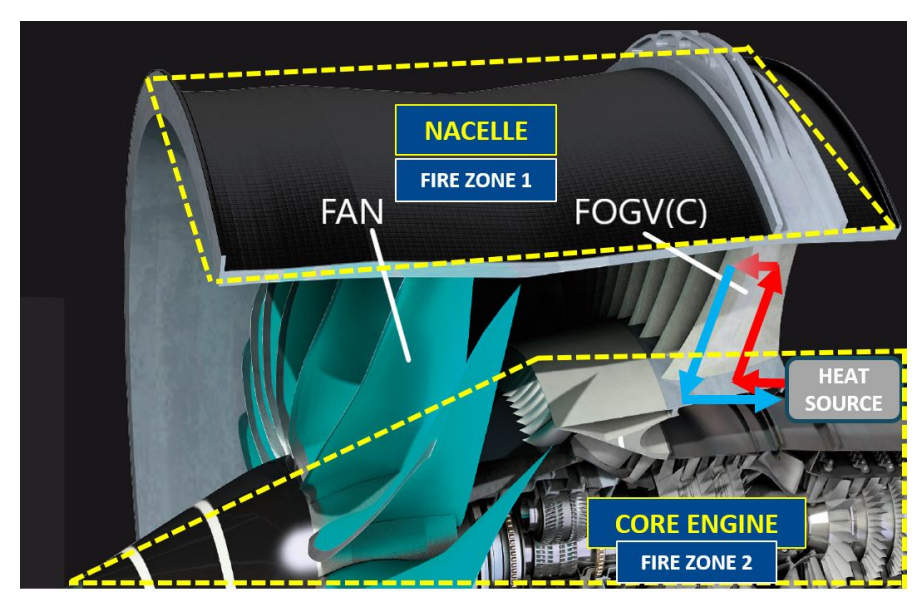

Figure 1. The FOGV assembly is located in the by-pass duct of an aero engine downstream of the fan between the fire zone 1 (nacelle) and 2 (core engine) (picture adapted with permission from [5]).

of fan-blade-off or bird-strike, are the current drawbacks of the integration of a heat exchanger in a FOGV. Regarding the thermal capability, the FOGVC, considered as a heat sink, belong to an oil system composed normally by a heat source, e.g. power gear box or electric generator, and an oil pump, between others components. To avoid oil transport between 2 fires zones (nacelle and core engine), the FOGVC-oil system is normally located in the core engine.

In the past, some investigations of the heat transfer, focused only on the air side, of Outlet Guide Vanes located after the Low Pressure Turbine (LPT-OGV), have been carried out in an experimental test facility located at the Chalmers University of Technology in Gothenburg (Sweden). Wang et al.([14], [15], [16]) studied experimentally and numerically the endwall heat transfer of LPT-OGVs using a heating foil on the air side and a thermochromic liquid crystal (LC) technique by the measurements. Rojo [17] researched the heat transfer using infrared thermography (IT) technique on the air side using electric heaters within an aluminium core and Jonsson et al. [18] employed the same measurement technique but heating the interior of the LPT-OGVs using hot water.

Focusing the investigation more on an airfoil heat exchangers, another name for FOGVC, Ito et al. [19] proposed the inverse heat transfer method, used to calculate the heat transfer coefficients of the heat exchanger, and tested experimentally it in a two air-to-refrigerant airfoil heat exchangers belonging to a intercooled recirculated (IR) gas turbine. In this investigation supercritical carbon dioxide and critical water have been used as refrigerants. In a second study Ito et al. [20] conducted experimental and 2D numerical CFD simulations of a cascade of airfoil heat exchangers to clarify the geometric effect of the shape of these kind of heat exchangers when water is used as heat transport medium (cooling fluid).

To accelerate the thermal integration of a cooler inside the FOGV, understanding it as the determination of the pressure drop of the internal fluid, the heat transmission through different domains (hot fluid-solid-coolant) and the internal temperature distribution, 3D numerical methods like the Finite Element Method (FEM) for structural and thermal simulations and the Finite Volume Method (FVM) for computational fluid dynamic simulations are suitable and common tools, instead of experimental tests due to associated high costs. The above numerical methods are implemented in the majority of multiphysic commercial softwares, like Ansys Fluent ${ }^{\mathrm{TM}}$ and Mechanical ${ }^{\mathrm{TM}}$ and offer the possibility to couple different modules providing high accurate results in very complex geometries. In contrast to high fidelity 3D aero-thermo-fluid simulations, alternative methods like analytical calculations, 1D simulations or 1D-3D coupled simulations may reduce the computational efforts maintaining at the same time an acceptable level of accuracy of the results. By the analytical calculations, the most simplified methodology, experimental correlations and 0-D equations (Nusselt correlations, Newton's law of cooling law, Fourier's conduction law,...) are employed to obtain a preliminary idea about the order of magnitude of the studied variables, whether the investigated 
geometry may be simplified on a way that the above equation are valid. Increasing the complexity of the methodology and assuming that secondary effects of the internal fluid are negligible, 1D and coupled 1D-3D numerical simulations can be employed in more complex geometries by using 1D FEM thermal elements (FLUID 116) in Ansys Mechanical ${ }^{\mathrm{TM}}$ [21] or the 1D thermo-fluid capabilities of the commercial software Flownex ${ }^{\mathrm{TM}}$ [22]. Other methodologies not investigated in this work, like the proposed by Nouri et al. [23] to predict the thermo-mechanical lifing of a turbine blade with internal cooling by using improved 1D-CFD based on 3D CFD simulations, may reduce the computational effort in aero-thermal systems.

In the present work, a comparison of the above 0D-1D-3D methodologies is presented providing a selection criteria when a determined level of accuracy in the simulations without prohibited computational times is desired.

\section{Methodology}

By the comparison of the different approaches, a simplified similar-to-real geometry of a FOGVC and a by-pass duct of a jet engine have been modeled using the CAD software Siemens $\mathrm{NX}^{\mathrm{TM}}$ version 12.0 and the open source software airfoiltools [24].
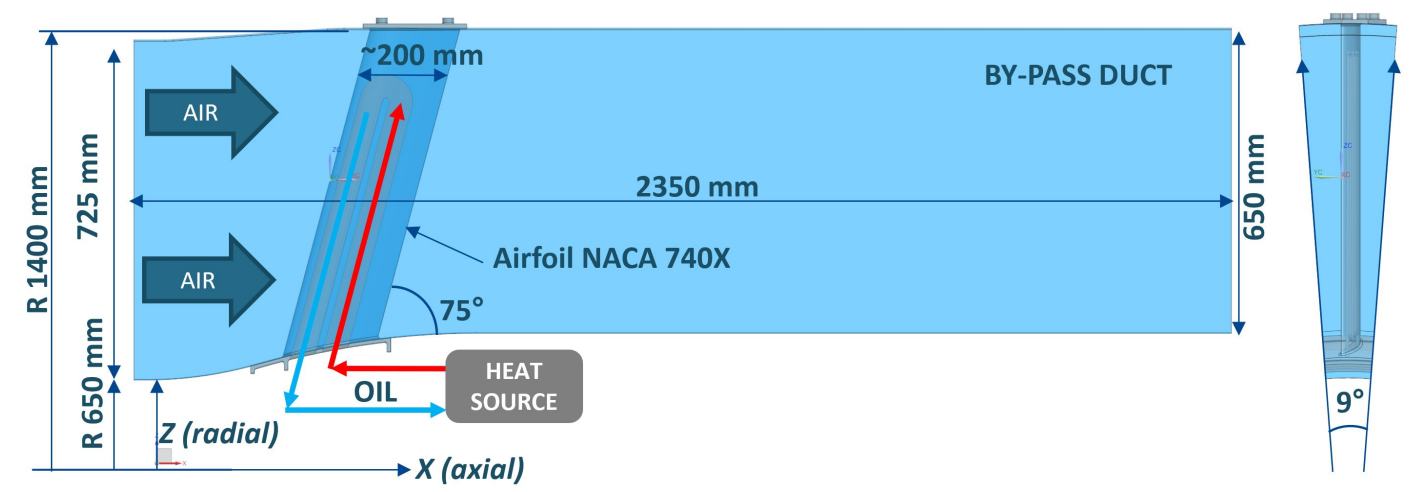

Figure 2. Geometrical dimensions of a simplified bypass duct-FOGVC assembly dimensions used in the simulations.

It is supposed that 40 FOGVCs belong to the FOGV-assembly and, due to the axisymmetric periodical symmetry, every FOGVC is located in a $9^{\circ}$ circumferential sector, picture 2 . Regarding the dimensions of the by-pass duct, in the axial position of the FOGVC there is a slight reduction of the cross section, from 725 to $650 \mathrm{~mm}$. The by-pass duct presents an axial total length of $2350 \mathrm{~mm}$, being the axial location of the FOGVC approx. ten times its chord length upstream from the outlet.

The FOGVC airfoil is based on a NACA 740X family having a chord length of circa $200 \mathrm{~mm}$ and a maximum total height of circa $725 \mathrm{~mm}$, with an inclination of $15^{\circ}$ relative to the radial direction, picture 2. Moreover the camber line presents at the leading edge an angle of $34^{\circ}$ relative to the axial direction to reduce the angle of attack of the air flow generated by the fan, picture 3. Within the FOGVC a virtual internal region has been defined, the design space, in which 2 concept designs have been modeled on a way that the internal oil cavities occupy the maximum volume inside. Between the design space and the air domain remains a uniform $3 \mathrm{~mm}$ thickness of metal to reduce the possibility of high stresses. The main geometrical dimensions of the 2 investigated concept design can be seen in the picture 3 : the concept design 1 (CD-1) presents the most simple internal cavity, an inverted $U$ with rectangular cross section $(4 \mathrm{~mm} \times 55 \mathrm{~mm})$. By the concept design 2 (CD-2), a coil internal cavity with a circular cross section has been used presenting 8 straight pipes and $7180^{\circ}$-bends with a diameter of $7.5 \mathrm{~mm}$ and a constant distance between the straight pipes of $12.75 \mathrm{~mm}$. The maximum length of the straight pipes is approx. $635 \mathrm{~mm}$ by both concept designs. 


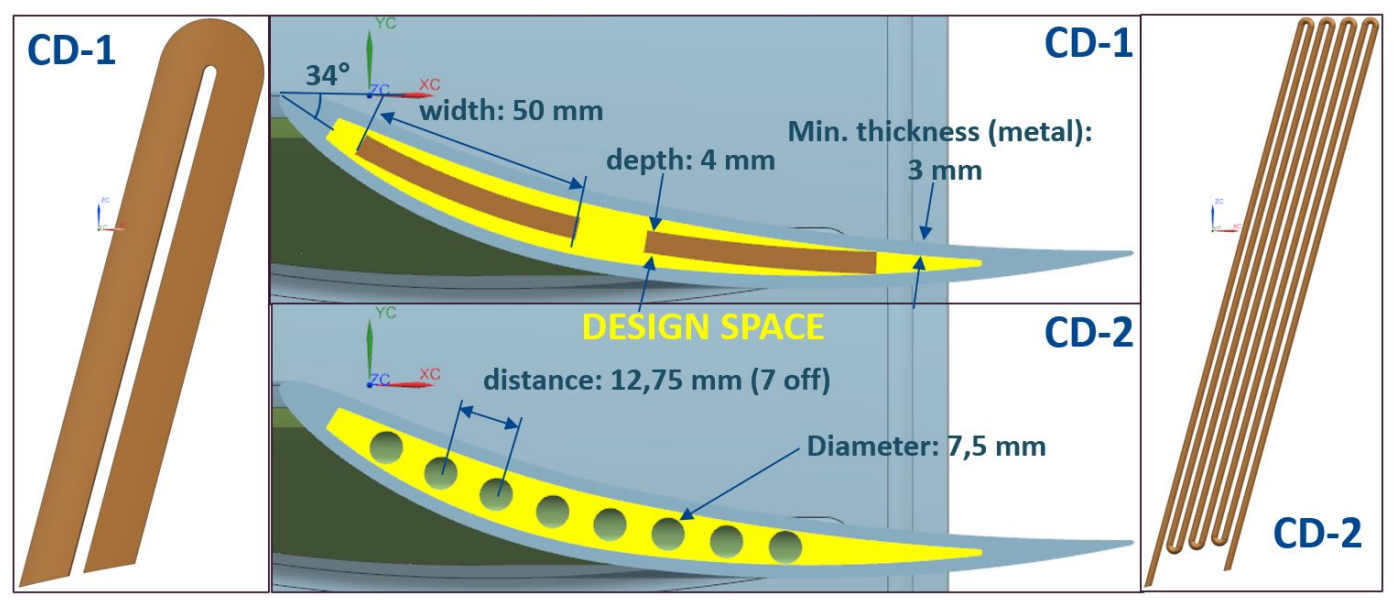

Figure 3. Geometrical dimensions of the investigated concept designs: the concept design 1 (CD-1) presents an inverted $U$ with rectangular cross section $(4 \mathrm{~mm} \times 55 \mathrm{~mm})$ meanwhile by the concept design 2 , a coil internal cavity with a $7.5 \mathrm{~mm}$ diameter circular cross section (CD-2) has been used presenting 8 straight pipes and $7180^{\circ}$-bends.

In the next step the approaches used in this work can be seen, picture 4: 4 levels of simplification have been defined (0: most complex; 3: simplest). Associated with, a lower number of domains have been simulated numerically reducing the computational effort but at the same time introducing stronger simplifications and assumptions by the analysis.
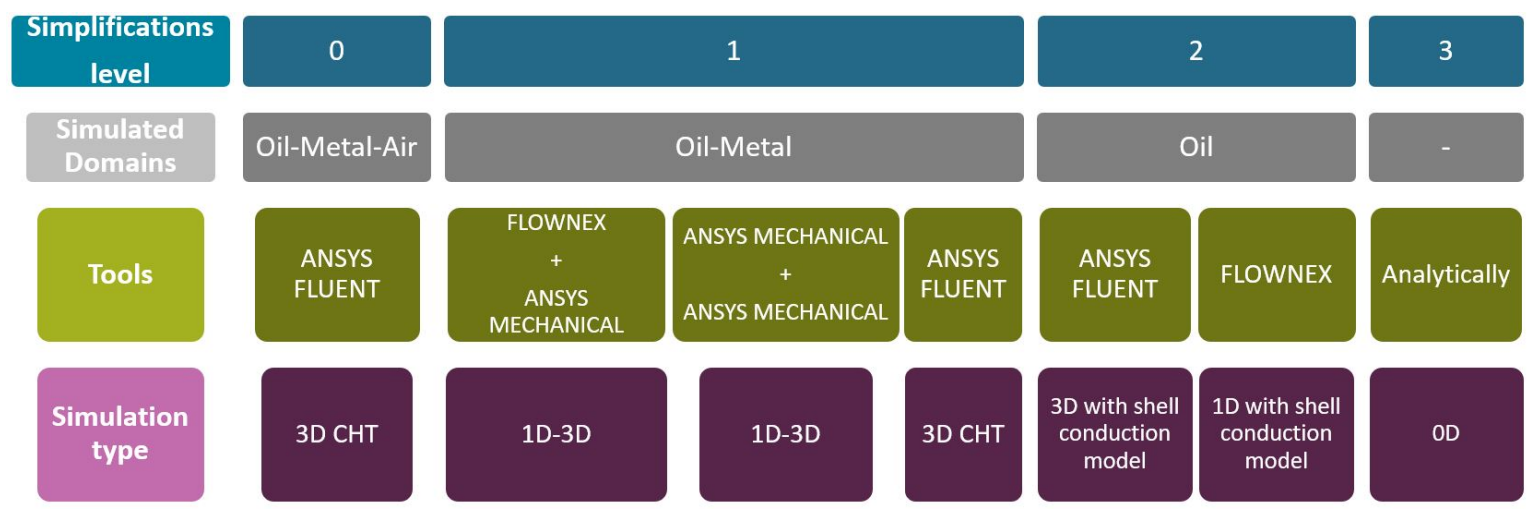

Figure 4. Approaches employed in this work: 5 simulation types (3D fully conjugate heat transfer with and without a thin wall model, 3D with a thin wall model, 1D-3D coupled, 1D and 0D) corresponding to 4 levels of simplification in 3 possible domains (oil, oil-metal and oil-metal-air) have been compared.

By the level 0 (L0) the whole aero-thermo-fluid system (Oil-Metal-Air: OMA) is simulated numerically using the conjugate heat transfer capabilities available in Ansys Fluent ${ }^{\mathrm{TM}}$. In this case, as boundary conditions, the values of the temperature, velocity and pressure at the inlet on the air side and the mass flow and inlet temperature on the oil side should be provided for the setup. By the next level, level 1, only the oil and metal domains (OM) are simulated substituting the air domain by a boundary condition of the third kind or Robin's condition (air free stream temperature + heat transfer coefficient) when Fluent ${ }^{\mathrm{TM}}$ or the coupling Flownex ${ }^{\mathrm{TM}}$-Mechanical ${ }^{\mathrm{TM}}$ approach is used. In case that by both oil and metal domain Mechanical ${ }^{\mathrm{TM}}$ is employed, an additional Robin condition for the OM interface must be provided using analytical equations. Reducing again the complexity of the approach, level 2, and analysing numerically only the oil domain (O), the metal domain is modeled by a shell conduction model, in which a constant thickness and thermal conductivity is applied. The same methodology as by the level 1, applying a Robin's condition on the OM interface, is employed both in Fluent ${ }^{\mathrm{TM}}$ and Flownex ${ }^{\mathrm{TM}}$. The simplest method, level 3, is based on analytical correlations with no numerical simulations involved. 
After the definition of the geometrical characteristics of the FOGVCs and the presentation of the approaches applied in this work, representative boundary conditions both in the oil and in the air domain have been defined. The worst case from the thermal point of view would take place when a predetermined part of the generated heat in the heat source can not be dissipated through the FOGVC provoking possible malfunctions. Considering the combination of thermo-fluid variables of the heat exchanger (mass flows and inlet temperatures), which define the FOGVC operation, low air mass flows (velocities) combined with low oil-to-air temperature differences and high oil mass flows have been investigated, table 1.

\begin{tabular}{|c|c|c|c|c|c|}
\hline \multirow[b]{2}{*}{$\begin{array}{l}\text { BOUNDARY } \\
\text { CONDITION }\end{array}$} & \multicolumn{2}{|c|}{ OIL } & \multicolumn{3}{|c|}{ AlR } \\
\hline & $\begin{array}{l}\text { Inlet Temp. } \\
\left({ }^{\circ} \mathrm{C}\right)\end{array}$ & $\mid \begin{array}{c}\text { Inlet Mass flow } \\
(\mathrm{kg} / \mathrm{s})\end{array}$ & $\begin{array}{l}\text { Inlet Temp. } \\
\left({ }^{\circ} \mathrm{C}\right)\end{array}$ & $\begin{array}{l}\text { Inlet Velocity } \\
(\mathrm{m} / \mathrm{s})\end{array}$ & $\begin{array}{c}\text { Inlet Pressure } \\
(\mathrm{Pa})\end{array}$ \\
\hline BC1-LO & \multirow{4}{*}{100} & 0,025 & \multirow{4}{*}{50} & \multirow{4}{*}{50} & \multirow{4}{*}{101325} \\
\hline BC2-LO & & 0,05 & & & \\
\hline BC3-LO & & 0,1 & & & \\
\hline BC4-LO & & 0,2 & & & \\
\hline
\end{tabular}

\begin{tabular}{|c|c|c|c|c|}
\hline \multirow{2}{*}{$\begin{array}{c}\text { BOUNDARY } \\
\text { CONDITION } \\
\text { (for levels } 1,2 \text { and } 3 \text { ) }\end{array}$} & \multicolumn{2}{|r|}{ OIL } & \multicolumn{2}{|r|}{ AIR } \\
\hline & $\begin{array}{c}\text { Inlet Temp. } \\
\left({ }^{\circ} \mathrm{C}\right)\end{array}$ & $\begin{array}{l}\text { Inlet Mass flow } \\
(\mathrm{kg} / \mathrm{s})\end{array}$ & $\begin{array}{c}\text { Inlet Temp. } \\
\left({ }^{\circ} \mathrm{C}\right)\end{array}$ & $\begin{array}{l}\text { Heat transfer coeff. } \\
\qquad\left(W / m^{2} k\right)\end{array}$ \\
\hline BC1 & \multirow{12}{*}{100} & 0,025 & \multirow{12}{*}{50} & 50 \\
\hline BC2 & & 0,05 & & 50 \\
\hline BC3 & & 0,1 & & 50 \\
\hline $\mathrm{BC4}$ & & 0,2 & & 50 \\
\hline BC5 & & 0,025 & & 100 \\
\hline BC6 & & 0,05 & & 100 \\
\hline BC7 & & 0,1 & & 100 \\
\hline BC8 & & 0,2 & & 100 \\
\hline BC9 & & 0,025 & & 150 \\
\hline BC10 & & 0,05 & & 150 \\
\hline BC11 & & 0,1 & & 150 \\
\hline $\mathrm{BC} 12$ & & 0,2 & & 150 \\
\hline
\end{tabular}

Table 1. Overview of the boundary conditions for the air and oil domain, depending on the simplifications level. The sub-table on the left is defined for level 0 (L0) meanwhile the sub-table on the right for the levels 1, 2 and 3 (L1, L2 and L3).

On the oil side, the mass flow through every FOGVC can take values from 0,025 to 0,2 kg/s with a inlet temperature of $100^{\circ} \mathrm{C}$ for all investigated cases. On the air side, the temperature $\left(50^{\circ} \mathrm{C}\right)$, pressure (atmospheric pressure at the see level, 1 bar) and velocity $(50 \mathrm{~m} / \mathrm{s}$ ) have been selected closed to the real boundary conditions established for the FOGV on the ground idle flight phase under the maximum hot day condition. Important to be pointed out about the air conditions is that depending on the employed simplification level, one or other variable would be needed for the setup. For example, by the L0 high fidelity 3D CHT simulations, the temperature, velocity and pressure at the inlet will be used (left sub-table in table 1), but in case that a more simplified level is used, the inlet temperature of the by-pass duct, employed as air free stream temperature, and the heat transfer coefficient are employed (right sub-table in table 1).

The comparison of the above methodologies at different levels of simplification and combined with the boundary conditions applied to 2 different concept designs contribute clearly to understand deeper the heat transmission and fluid mechanisms which take place in an oil-to-air Fan Outlet Guide Vane Cooler (FOGVC).

\section{Analytical assessments}

The analytical assessments belong to the simplification level 3, only analytical equations and correlations based mainly on empirical results, are used to determine the pressure drop of the oil system and the heat transmission between the hot oil and the air, assuming strong simplifications.

\subsection{Heat transfer}

In the determination of the transmitted heat within the heat exchanger and the oil outlet temperature, some simplifications have been used. By the first one, the flow over the FOGVC is idealized as a parallel flow over a flat plate, due to the low total thickness and relative angle of the flow respect to the curvature of the airfoil. The next simplification is based on how the heat is transmitted between the 2 fluid domains, in this case, only perpendicular to the flat plate and one dimensional but assuming that through the laterals of the oil cavities takes place a part of the dissipation. This 
quantification is obtained more exact in L0, L1 and L2. Regarding the heat transfer mechanisms used in this work, and due to the low oil-to-air temperature differences, the radiation heat transmission is considered negligible. The last simplification refers to the fact that the oil cavities are only located in the root of the FOGVC and within the airfoil. Assuming for the L3 that the main heat exchange takes place through the airfoil, it is acceptable to use as dissipation area either the oil-metal interface, the metal-air interface or an average of both. The decision, which dissipation area is employed in the analytical correlations, has a big impact, as it will be shown later, in the dissipated heat and the oil outlet temperature.

The combination of the above simplifications allow to reformulate the 3D study in the FOGVC as a 1D steady-state metal wall analysis with the following heat transfer mechanisms: internal forced flow heat convection between the oil and the metal domain, conduction through the metal part and external forced flow heat conduction with the air. As no internal generation of thermal energy exists within the metal wall, and applying the energy conservation law to the simplified 1D plane wall, the total heat transfer rate in the FOGVC, $q_{o a}$, keeps constant through all interfaces $q_{o a}=q_{o m}=q_{m}=q_{m a}$, where $q_{o m}$ and $q_{m a}$ is the convective heat rate at the oil-metal and metal-air interface, respectively, and $q_{m}$ the conduction heat rate. Using the Newton's law of cooling for the convective term

$$
q=h A\left(T^{\text {surface }}-T^{\text {free stream }}\right)=h_{\text {om }} A\left(T_{o m}-T_{o}^{\infty}\right)=h_{m a} A\left(T_{m a}-T_{a}^{\infty}\right)
$$

and the Fourier's law for the heat conduction:

$$
q_{m}=k_{m} A \frac{\Delta T}{L}=\frac{k_{m} A}{L}\left(T_{o m}-T_{m a}\right)
$$

where, $h$ is the convection heat transfer coefficient $\left(h_{o m}\right.$ and $h_{m a}$ in the oil-metal and metal-air interface, respectively ), $A$ is the dissipation area, $k_{m}$ and $L$ is the thermal conductivity and thickness of the solid domain and $T_{o m}-T_{m a}$ the temperature difference between both interfaces, a general expression for the heat rate through the FOGVC is obtained as followed:

$$
q_{o a}=\frac{\left(T_{o}^{\infty}-T_{a}^{\infty}\right)}{\frac{1}{h_{o m} A}+\frac{L}{k A}+\frac{1}{h_{m a} A}}=\frac{\left(T_{o}^{\infty}-T_{a}^{\infty}\right)}{R_{o m}+R_{m}+R_{m a}}=U A\left(T_{o}^{\infty}-T_{a}^{\infty}\right)
$$

Applying a electric analogy to the FOGVC thermal circuit, 3 thermal resistances can be identified on the equation 3: $R_{o m}, R_{m}$ and $R_{m a}$ but only the $R_{m}$ can be calculated without further analysis because is composed of known variables. Moreover an overall heat transfer coefficient, $U$, can be defined based on the total thermal resistance of the wall plate. The main drawback of the equation 3 to determine the total dissipated heat and the outlet oil temperature is that the $T_{0}^{\infty}$ is unknown. An option to overcome that is the log mean temperature difference (LMTD) method [25], but due to its iterative nature and alternative method is preferred. The number of transfer units (NTU) method solve this issue relied only on the effectiveness of the heat exchanger $\epsilon$, the minimum heat capacity rate of the fluids, $C_{\min }=\left(\dot{m} c_{p}\right)_{\min }$, and the temperature difference of the fluid at the inlets:

$$
q_{o a}=\epsilon C_{\min }\left(T_{o, \text { in }}^{\infty}-T_{a}^{\infty}\right)
$$

Key factor by the NTU method is the determination of the effectiveness $\epsilon=\frac{q_{o a}}{q_{\max }}$ with values staying between 0 and 1. An alternative definition of $\epsilon$ for any heat exchanger [25] based on the heat capacity ratio, $C_{r}=\frac{C_{\min }}{C_{\max }}$ and the number of transfer units $(N T U)$ is:

$$
\epsilon=f\left(N T U, \frac{C_{\min }}{C_{\max }}\right)=f\left(N T U, C_{r}\right)
$$


being the definition of NTU as followed,

$$
N T U=\frac{U A}{C_{\text {min }}}
$$

There are available some expressions of the equation 5, depending mainly on the type of the heat exchanger (parallel- or counter-flow, shell-and-tube, cross-flow with simple pass) and on $C_{r}$. In table 2 are summarized the values of $C_{\text {min }}, C_{\max }$ and $C_{r}$ being the same for CD1 and CD2.

\begin{tabular}{|c|c|c|c|c|}
\hline & \multicolumn{4}{|c|}{ Oil inlet mass flows ( $\mathrm{kg} / \mathrm{s})$} \\
\hline & 0,025 & 0,05 & 0,1 & 0,2 \\
\hline$C_{\min }$ (oil) & 53,4 & 106,8 & 213,7 & 427,3 \\
\hline$C_{\max }$ (air) & \multicolumn{4}{|c|}{6359,1} \\
\hline$C_{r}$ & 0,008 & 0,017 & 0,034 & 0,067 \\
\hline
\end{tabular}

Table 2. NTU method: heat capacity rates of oil, $C_{\min }$, air, $C_{\max }$, and associated heat capacity ratios, $C_{r}$, for CD1 and CD2.

The results show that the air capacity rate is much larger than that of the oil, meaning that the air temperature remains almost constant after the FOGVC. As the values of $C_{r}$ stay very closed to 0 , this value is assigned to $C_{r}$, being valid the following equation for the assessment of the effectiveness:

$$
\epsilon=1-e^{(-N T U)}
$$

To confirm that the equation 7 is valid for our purpose, a comparison with $\epsilon$-expressions for a counter-flow and a cross-flow with unmixed fluids heat exchanger has been made with differences under $1 \%$ confirming the validity of the assumption.

The last step to assess the heat transfer using the NTU method is the determination of the number of units of the heat exchanger using the equation 6. For that, the overall heat transfer coefficient and the dissipation area should be assessed. Before the assessment of $U$ is explained, the decision about which dissipation area is used for the 2 interfaces in the calculations is needed. As dissipation area can be used the oil-metal interface area (smallest area), $A_{o m}^{C A D}$, the average method proposed in [26]: $A=\frac{A_{o m}+A_{m a}}{\ln \left(\frac{A_{m a}}{A_{o m}}\right)}$, the arithmetic mean of the 2 interfaces: $A=\frac{A_{o m}+A_{m a}}{2}$, or the metal-air interface area with the highest value, $A_{m a}^{C A D}$. In the table 3 can be seen the total values for the CD1 and CD2 and the augmentation heat rate factors resulting by comparing the above proposed dissipation areas with the

\begin{tabular}{|c|c|c|c|c|c|c|c|c|c|}
\hline \multirow{2}{*}{$\begin{array}{l}\text { CONCEPT } \\
\text { DESIGNS }\end{array}$} & \multicolumn{5}{|c|}{ Dissipation Areas $\left(\mathrm{m}^{2}\right)$} & \multicolumn{4}{|c|}{ Augmented heat rate factors } \\
\hline & $\begin{array}{l}\text { A-CAD-OM } \\
\text { Oil-Metal }\end{array}$ & $\begin{array}{c}\text { A1 } \\
\text { Oil-Metal }\end{array}$ & $\begin{array}{c}\text { A2 } \\
\text { Average } \\
\end{array}$ & $\begin{array}{c}\text { A3 } \\
\text { Arithmetic }\end{array}$ & $\begin{array}{l}\text { A-CAD-MA } \\
\text { Metal-Air }\end{array}$ & \multicolumn{3}{|c|}{ (reference: A-CAD-OM) } & A-CAD-MA \\
\hline CD1 & 0,143 & 0,1517 & 0,209 & 0,215 & & 1,06 & 1,45 & 1,50 & 1,94 \\
\hline CD2 & 0,110 & 0,113 & 0,183 & 0,196 & 0,210 & 1,03 & 1,67 & 1,78 & 2,53 \\
\hline
\end{tabular}
CAD's measurement of the oil-metal interface, the smallest one.

Table 3. Proposal of dissipation areas by the analytical calculations for CD1 and CD2 and associated increases of the dissipated heat rates in the FOGVC.

The results show that the augmentation of the heat rate varies between 1.5 and 2.5 times the heat rate in comparison when the smallest area, $A_{o m}^{C A D}$, is employed. By using $A_{m a}^{C A D}$, the highest augmentation factor is introduced in the calculations obtaining too optimistic heat rates, which could provoke malfunction and overheating in the heat source. One alternative would be $A_{1}$, but as later shown by the numerical results (L0, L1 and L2), the heat dissipation is not only concentrated in the vicinity of the oil cavities but in an wider area, which means that $A_{2}$ and $A_{3}$ are better alternatives to be used. Due to the above reasons, $A_{3}$ is a good compromise for the thermal resistances. 
Now is possible the assessment of the metal thermal resistances for CD1, $R_{m}^{C D 1}=\frac{L}{k A_{3}}=0.0018 \mathrm{~K} / \mathrm{W}$, and $\mathrm{CD} 2, R_{m}^{C D 2}=0.002 \mathrm{~K} / \mathrm{W}$.

To calculate the heat transfer coefficient of the metal-air interface, $h_{m a}$, needed to determine the thermal resistance $R_{m a}$, the following expression is employed:

$$
h_{m a}=\frac{N u_{x} k_{a}}{x}
$$

where $N u$ represents the non-dimensional Nusselt number, $k_{a}$ the thermal conductivity of the air and $x$ a characteristic length where the $N u$ number is assessed. Nusselt convection correlations of a external flow over a flat plate, semi-empirical equations depending on the non-dimensional numbers $R e$ and $\mathrm{Pr}$, are employed to determine the $\mathrm{N} u$ number. To know which correlation is suitable to our problem is needed to know the location on the airfoil where the flow changes from laminar to turbulent. Using the recommendation of Incropera et al.[25] for external flows, this transition takes place where the $R e=R e_{\text {critical }}=5 \cdot 10^{5} \rightarrow x_{\text {critical }}=\frac{R e_{\text {critical }} \mu_{a} \mu_{a}^{\infty}}{\rho_{a}}$, being $\mu_{a}, \rho_{a}$ and $u_{a}^{\infty}$ the dynamic viscosity, the density and the free stream velocity of the air, respectively. For our airfoil, with a chord length of $0.2 \mathrm{~m}$, the $x_{\text {critical }}=0.179 \mathrm{~m}$ is located very closed to the trailing edge. Hence, 2 possible Nusselt correlations can be used, assuming the use of average values for $h_{m a}$ with $x=L=0.2 \mathrm{~m}$ instead of local one:

$$
\overline{N u}_{x}=\left(0.037 \operatorname{Re}_{L}^{\frac{4}{5}}-871\right) \operatorname{Pr}^{\frac{1}{3}} \quad R e_{L} \leq 10^{8}, \quad 0.6 \leq \operatorname{Pr} \leq 60
$$

By the equation 9 , the average Nusselt number, $\overline{N u}_{x}$, is assessed assuming a mixed flow. As the laminar flow is presented over circa $89 \%$ of the whole chord length, an alternative Nusselt correlation for laminar flows can be used:

$$
\overline{N u}_{x}=0.664 \operatorname{Re}_{x}^{\frac{1}{2}} \operatorname{Pr}^{\frac{1}{3}}
$$

The assessment of the non-dimensional numbers $R e_{a}=\frac{\rho_{a} u_{a}^{\infty} L}{\mu_{a}}$ and $P r_{a}=\frac{\mu_{a} c_{p a}}{k_{a}}$, being $c_{p a}$, the specific heat, is carried out as followed: the ideal gas law [27] is used to determine the air density, $\rho_{a}$ :

$$
\rho_{a}=\frac{P_{a}}{R T_{a}}
$$

where $R$ the ideal gas constant and $P_{a}$ and $T_{a}$ the pressure and temperature of the air are, respectively. By the air dynamic viscosity, $\mu_{a}$, the Sutherland's Law with 3 coefficients is used [27]:

$$
\mu_{a}=\mu_{0}\left(\frac{T}{T_{0}}\right)^{\frac{3}{2}} \frac{T_{0}+S}{T+S}
$$

taking the reference viscosity, $\mu_{0}$, the value $1.716 \cdot 10^{-5} \mathrm{~kg} / \mathrm{ms}$ and the reference temperature, $T_{0}=$ $273.11 \mathrm{~K}$. S is the effective temperature or Sutherland constant with a value of $110.56 \mathrm{~K}$. The last two material properties of the air to be calculated are the specific heat, $c_{p a}$ and the thermal conductivity $k_{a}$. By the specific heat, a $3^{\text {rd }}$-degree polynomial function of $\mathrm{T}$ is used [27]:

$$
c_{p}=C_{0}+C_{1} T_{a}+C_{2} T_{a}^{2}+C_{3} T_{a}^{3}
$$

where the coefficients $C_{0}, C_{1}, C_{2}$ and $C_{3}$ take empirical values. In the case of the thermal conductivity, $k_{a}$, a parabolic function of $\mathrm{T}$ with empirical coefficients is used:

$$
k_{a}=D_{0}+D_{1} T_{a}+D_{2} T_{a}^{2}
$$

Knowing the above material properties for the air, the $P r_{a}$ and $R e_{a}$ number take the values 0.71 and $5.59 \cdot 10^{5}$, respectively and using the flat plate correlation for mixed flow, equation 9 , a heat transfer coefficient of $73.2 \mathrm{~W} / \mathrm{m}^{2} \mathrm{k}$ is obtained, presenting a difference of circa $16 \%$ to the results obtained 
with the laminar correlation $61 \mathrm{~W} / \mathrm{m}^{2} \mathrm{k}$. In order to obtain a better understanding of the air side heat transmission, a range of $h_{m a}$ between 50 and $150 \mathrm{~W} / \mathrm{m}^{2} \mathrm{~K}$ instead of the above analytical values has been employed as boundary condition in the numerical simulations at levels L1 and L2, see table 1. As the transition laminar-to-turbulent take places over the FOGVC surface, the heat transfer coefficient for mixed flow will be used to calculate the air thermal resistance, being $R_{m a}^{C D 1}=\frac{1}{h_{m a} A_{3}}=0.0615 \mathrm{~K} / \mathrm{W}$ and $R_{m a}^{C D 2}=0.0697 \mathrm{~K} / W$. Actually only one thermal resistance for the air side is needed, if the dissipation area is constant. In our case, the dissipation area is an average of the 2 fluid-solid interfaces making needed the assessment of a second thermal resistance for CD2.

The last thermal resistance to be determined corresponds to the internal flow in the oil side, $R_{o m}$. For that, a similar process, as by the external flow, is followed to assess $R_{m a}$ but with some differences. Within the oil internal cavity, the fluid is confined by the o-m interface appearing two regions: entrance region (hydrodynamic and thermal) and the full developed region. In this work only correlations for fully developed flows are employed to simplify the calculations following the recommendations of Incropera et al. [25]. For laminar flows ( $R e<2300)$, like in CD1 with all mass flows and by CD2 with 0.025 and $0.05 \mathrm{~kg} / \mathrm{s}$, when $P r>>1$ (in our case $P r=70.2$ at the inlet), or by turbulent flows outside of the entry length, defined as $x_{\text {entrance length }}>10 D_{h}$, being $D_{h}$ the hydraulic diameter, this is a reasonable assumption. Another difference with the air side methodology, in which the $T_{a}^{\infty}$ is a constant, is that in the oil side an estimation of a mean temperature alongside the oil cavity, $T_{0}^{\infty}$, is needed to evaluate the material properties of the oil due to the variation of the oil temperature from the inlet to the outlet. In this work and using a constant surface temperature condition, an arithmetic mean temperature approach has been used, obtaining a mean oil temperature of $87.5^{\circ} \mathrm{C}$ when supposed a oil outlet temperature of $75^{\circ} \mathrm{C}$. Moreover the oil used for this assessment is a common jet engine oil MIL-L-23699 (5cSt). Now is possible to evaluate $R e_{0}$ for the different mass flows, obtaining that only laminar flows are present by CD1, figure 5 . By CD2, turbulent flows appears clearly when the two highest mass flows are employed.

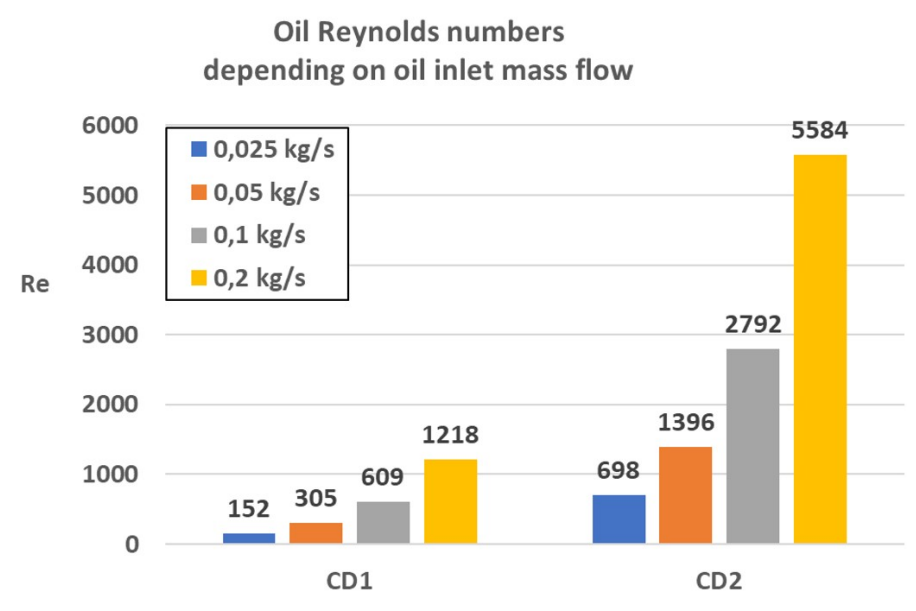

Figure 5. Oil Reynolds numbers corresponding to the analytical assessments using the arithmetic mean approach by CD1 and CD2.

The values of the Nusselt numbers in laminar flows for pipes with circular cross section do not depend on the Reynolds numbers, being a constant, 3.66. By rectangular cross sections, the Nusselt number varies depending on the ratio $\frac{\text { height }}{\text { width }}$. Ratios higher as 8 are considered as 'infinite' ratio corresponding to a constant Nusselt number of 7.54 [25]. By the turbulent flows, however, the Nusselt number are assessed using more complex correlations in which the roughness of the wetted surface 
and friction effect play an important role. In this work is used the correlation for smooth pipes and valid for the investigated range of Reynolds numbers, provided by Gnielinski [25]:

$$
N u_{o}=\frac{\left(\frac{\lambda}{8}\right)\left(R e_{o}-1000\right) P r_{o}}{1+12.7\left(\frac{\lambda}{8}\right)^{\frac{1}{2}}\left(\operatorname{Pr}_{o}^{\frac{2}{3}}-1\right)}
$$

where $\lambda$ is the Darcy friction factor [28], which depends on the flow regime, that is, on $R e$. For turbulent flows in smooth surfaces for circular pipes, in the range $2300<R e<10^{7}$, three correlations can be employed: the correlation of Konakov [28]:

$$
\lambda_{t}=\frac{1}{\left(1.8 \log _{10} R e_{o}-1.5\right)^{2}}
$$

the Petukhov's correlation [25]:

$$
\lambda_{t}=\frac{1}{\left(0.79 \log R e_{o}-1.64\right)^{2}}
$$

or for a global range of $R e$, based on the values of the laminar and Konakov's correlations [28]:

$$
\lambda_{\text {global }}=\left(\lambda_{l}^{3}+\lambda_{t}^{3}\right)^{\frac{1}{3}}
$$

being defined $\lambda_{l}$ for $\operatorname{Re}<2300$ as:

$$
\lambda_{l}=\frac{64}{R e_{0}}
$$

In equation (19) an additional factor, $f_{\text {rect }}$, can be introduced [28] to take into account friction effects by rectangular cross sections like by $\mathrm{CD} 1$ :

$$
\lambda_{l}=f_{\text {rect }} \frac{64}{\operatorname{Re}_{0}}
$$

The $f_{\text {rect }}$ depends mainly on the ratio of the dimensions of the cross section $\left(\frac{h e i g h t}{w i d t h}\right)$ presenting a monotonically decreasing behaviour, see figure 6 . For square cross sections (ratio $=1$ ), the $f_{\text {rect }}$ takes the lowest value, 0.89 , provoking a reduction of the Darcy-factor of $11 \%$ in comparison with the circular cross section case. No impact of the geometric dimensions on the friction factor $\left(f_{\text {rect }}=1\right)$ takes place when the ratio is equal to 0.44 .

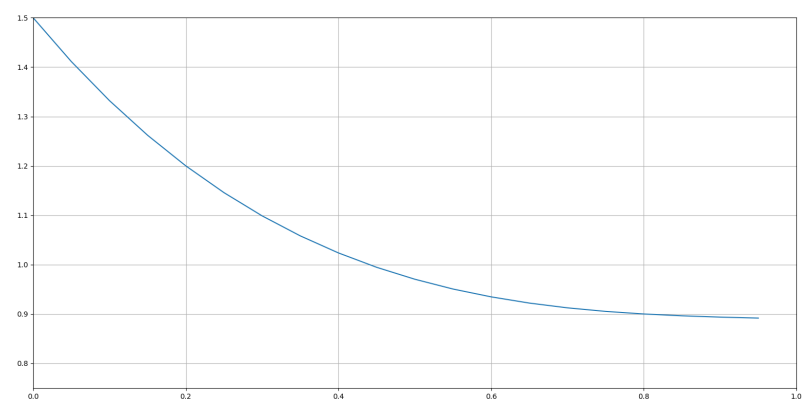

Figure 6. Influence of the geometric dimensions of the cross section over the Darcy-friction factor in laminar flows $f_{\text {rect }}$, (based on figure 70 by [28]). 
By the CD1 geometry with a geometrical ratio of 0.0727 , the factor $f_{\text {rect }}=1.374$ and the friction factor results 87.93. This value is lower as the proposed in [25], 96, by using the expression for laminar and rectangular cross sections:

$$
\lambda_{l}=\frac{96}{R e_{0}}
$$

A comparison of the friction factor values obtained in equation 20 and 21 is made by the assessment of the pressure drop in the next chapter to estimate a possible influence on the fluid variables but not by the impact in the heat transfer because in laminar flows the friction factor is not considered by the equations.

Finally, all needed ingredients are known to assess analytically the total dissipated heat in the FOGVC (equations 3 and 4) and the outlet temperature of the oil for the predetermined boundary conditions. The following figures summarize the most important results of the analytical calculations. In the figures 7,8 and 9 can be seen the results by fixing the air heat transfer coefficient $h_{m a}$ to the obtained value $73.2 \mathrm{~W} / \mathrm{m}^{2} \mathrm{~K}$. On the contrary, in the figures 10 and 11 the results show the influence of the air heat transfer coefficient varying the range from 50 to $150 \mathrm{~W} / \mathrm{m}^{2} \mathrm{~K}$ in the global thermal analysis.

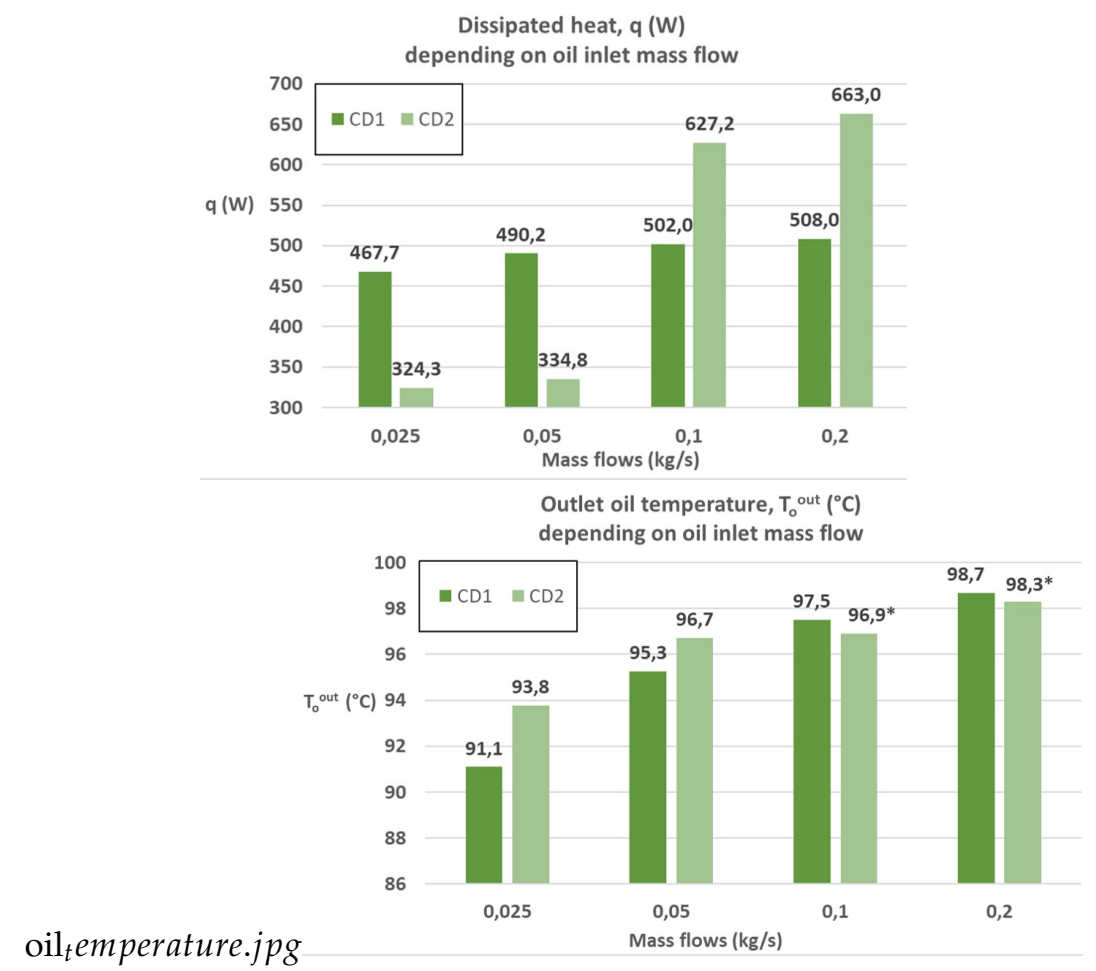

Figure 7. Comparison of the dissipated heat (left) and the outlet oil temperature (right) using $h_{m a}=$ $73.2 \mathrm{~W} / \mathrm{m}^{2} \mathrm{~K}$ by $\mathrm{CD} 1$ and $\mathrm{CD} 2$ depending on the feeding oil mass flow rates.

The picture 7, (left), shows the evolution and comparison of the dissipated heat depending on the oil inlet mass flow by CD1 and CD2. In CD1 the increment of the mass flow has a very low impact on the dissipation heat achieving a maximum improvement of only $40 \mathrm{~W}$ (from 467.7 to 508). By CD2, on the contrary, exists a clear improvement when the mass flow achieves the value $0.1 \mathrm{~kg} / \mathrm{s}$ on which the laminar flow changes to transition one, obtaining maximal improvements of circa $105 \%$ (from $324.3 \mathrm{~W}$ to $663 \mathrm{~W}$ ). The change of the behaviour between laminar and transition flows will be clearly shown in the following sections when another results are presented. The effect of mass flow increment on the outlet temperature can be seen in the right side of picture 7, provoking a lower reduction of temperature descend between inlet and outlet. To be remarkable is that neither of the concept designs are able to reduce the inlet temperature beyond $10^{\circ} \mathrm{C}$. In case that the lowest outlet temperature is the 
selected design variable, CD1 fulfills this requirement, when the mass flows remain below $0.1 \mathrm{~kg} / \mathrm{s}$, hence, in laminar range.

The influence of different friction factor correlations over the oil convection heat transfer coefficient and the Nusselt number by turbulent flows in CD2 can be seen in picture 8, (left). No significant differences (below $2 \%$ by $N u_{o}$ and $h_{o m}$ ) have been obtained by comparing the three correlations (Petukhov, Konakov and global range correlation) using the highest mass flow. The Petukhov's correlation is employed for the rest of the analytical calculations as the values provided by the other 2 correlations are more extreme.

To optimize the thermal behaviour of the FOGVC, it is needed to know which side of the heat exchanger provokes a higher thermal resistance by the heat transmission. This information is presented by figure 8 , (right).

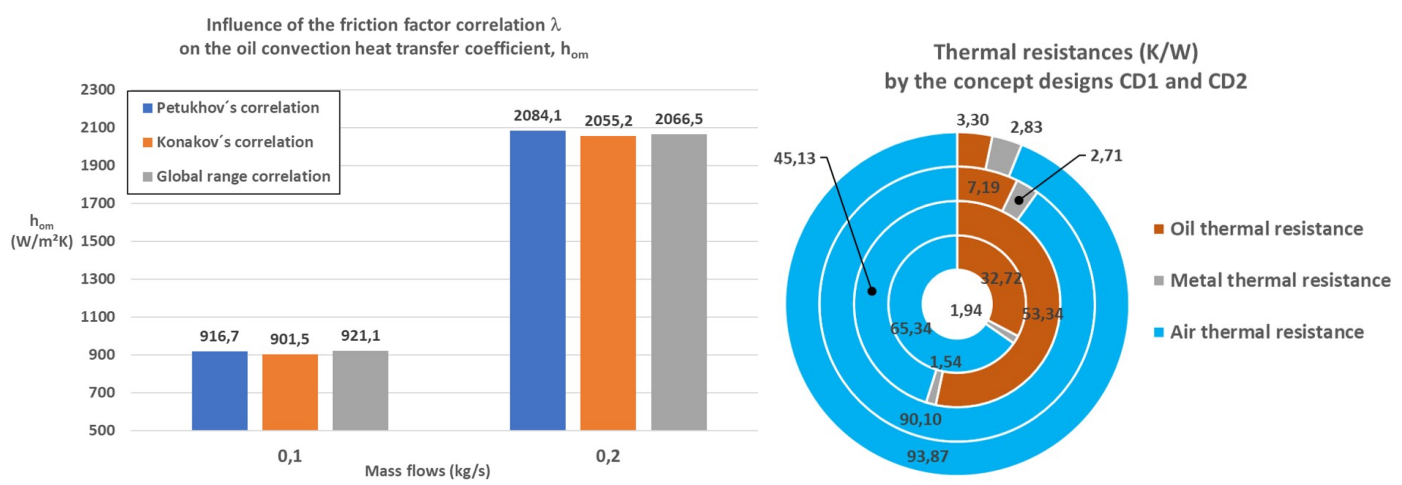

Figure 8. Comparison of the influence of different friction factor correlations over the oil convection heat transfer coefficient by turbulent flows in CD2 (left) and thermal resistances of the CD1 (only one ring is needed, the most internal one, to represent the laminar flow regime in the whole range of investigated mass flows) and CD2 (three external rings are needed: the first most internal represents the constant thermal resistances by the laminar flows: 0.025 and $0.05 \mathrm{~kg} / \mathrm{s}$, and the two most external corresponds to the turbulent flows: 0.1 and $0.2 \mathrm{~kg} / \mathrm{s}$, respectively) using as friction factor the Petukhov's correlation and $h_{m a}=73.2 \mathrm{~W} / \mathrm{m}^{2} \mathrm{~K}$ (right).

Using a constant heat transfer coefficient on the air side $\left(h_{m a}=73.2 \mathrm{~W} / \mathrm{m}^{2} \mathrm{~K}\right)$, the thermal resistances of $\mathrm{CD} 1$ are represented in the most internal ring of the graphic. Only 1 ring is needed by $\mathrm{CD} 1$ due to the laminar nature of the investigated flows. In this case with an air thermal resistance of $65.34 \%$, the air side is restricting the heat dissipation coming from the oil side. Hence, the air side should be improve instead of the oil cavities, e.g by increasing the air velocity or the dissipation area. In CD2 something similar is happening, but more extreme, by the most external ring $(0.2 \mathrm{~kg} / \mathrm{s})$ and the second more external one $(0.1 \mathrm{~kg} / \mathrm{s}$ ) with air thermal resistances over $90 \%$ (both transition flows in the oil side). The laminar cases of CD2 $(0.025$ and $0.05 \mathrm{~kg} / \mathrm{s})$, represented by the ring with values: oil $=53.34 \%$, metal $=1.54 \%$; air $=45.13 \%$, is the only one in which the oil thermal resistance is higher than the air one but with values quite similar to the air side. A configuration with similar thermal resistances on both fluid sides is recommended to avoid bottlenecks by the heat dissipation. Regarding the conduction metal thermal resistances, all remain below $3 \%$ by both concept designs. The reduction of the metal resistance normally is related with structural issues, as to reduce this resistance is needed to reduce the thickness of the oil-air wall and/or the increase of the thermal conductivity of the FOGVC material, which normally is not possible due to structural requirements.

To know the dissipation potential of the FOGVC, the concept of effectiveness, $\epsilon$, and the maximum possible heat transfer rate, $q_{\max }$, defined in the NTU method can be used, figure 9 . 

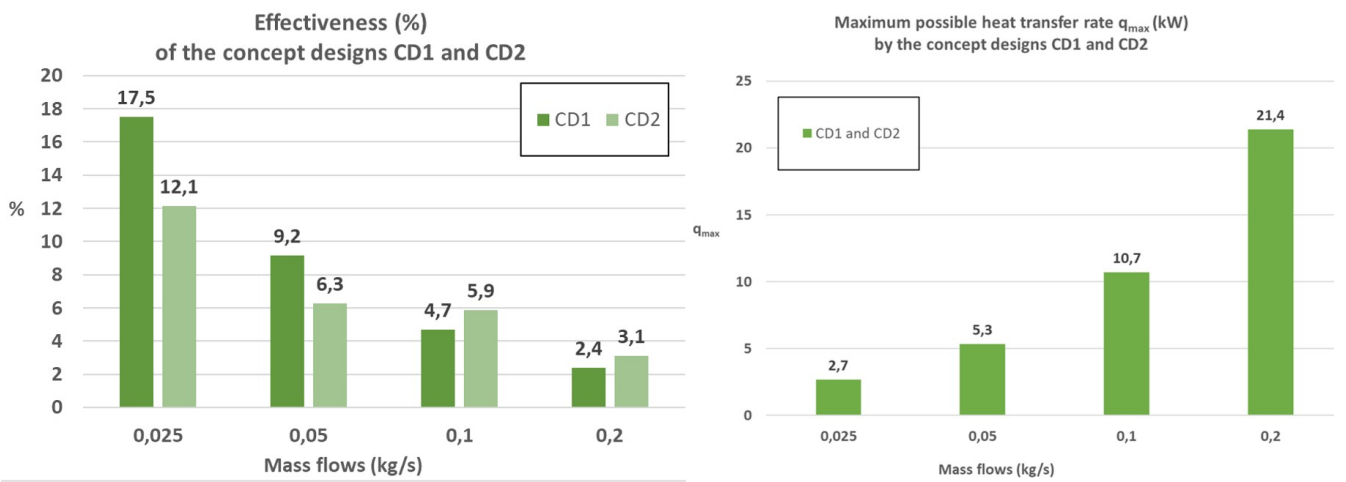

Figure 9. Effectiveness $\epsilon$ (\%) (left) and maximum possible heat transfer rate, $q_{\max }(k W)$ (right) of the concept designs CD1 and CD2.

Based only on the heat capacities and the inlet temperatures of both fluids in the FOGVC, the theoretically maximum possible heat transfer rate, independent of the employed concept design, increases linearly with the mass flow, obtaining a maximum value of $21.4 \mathrm{~kW}$. If in every FOGV is integrated a heat exchanger, the theoretical total dissipation heat rate of the FOGVC assembly can achieve $856 \mathrm{~kW}$ (assuming 40 FOGVCs). Unfortunately the effectiveness of the FOGVC decreases with the increment of the mass flow and the type of design, as can be shown in the left graphic of the picture 9 , obtaining the total heat transfer rate multiplying both variables, see left graphic of figure 7 .

Until now a constant air heat transfer is employed. Now, the influence of the air heat transfer coefficient variation is investigated, figure 10.
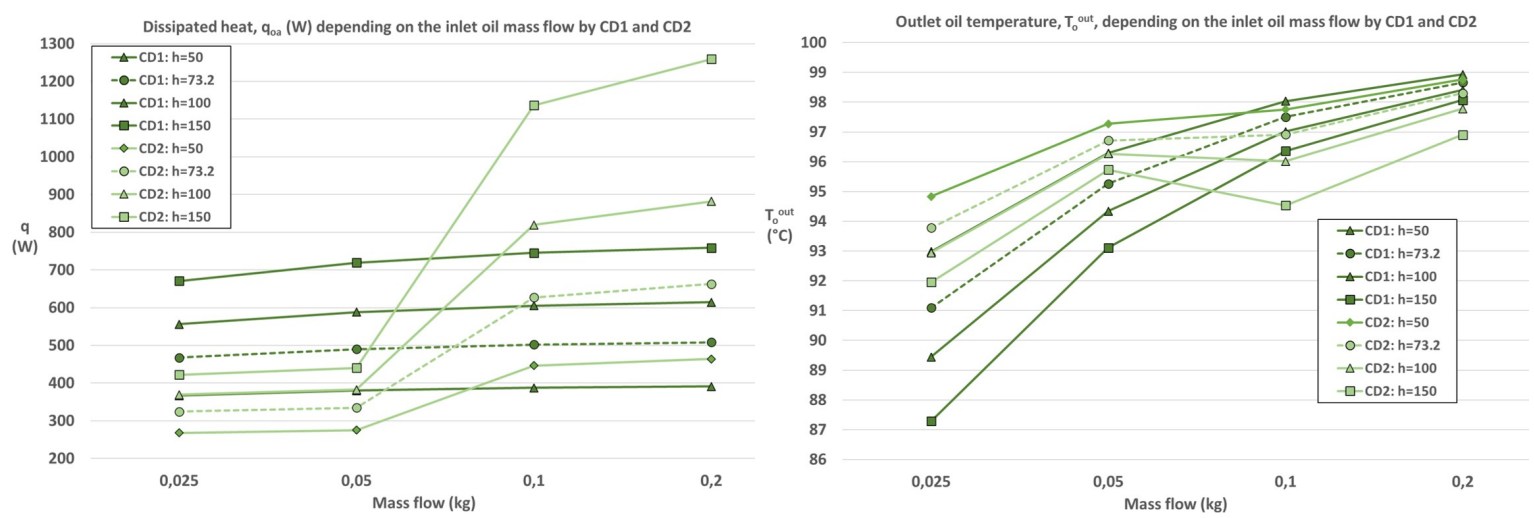

Figure 10. (left) and (right) of the concept designs CD1 and CD2.

Regarding the dissipated heat rate by CD1, a slight continuous increase takes place, when the oil mass flow is augmented. A higher impact has the increment of the air heat transfer coefficient (from 50 to $150 \mathrm{~W} / \mathrm{m}^{2} \mathrm{~K}$ ), provoking maximal improvements of circa 95\% (BC12). By CD2 the transition from laminar to transition flows has a huge impact on the heat dissipation causing increments between $62 \%\left(h_{m a}=50 \mathrm{~W} / \mathrm{m}^{2} \mathrm{~K}\right)$ and $158 \%\left(h_{m a}=150 \mathrm{~W} / \mathrm{m}^{2} \mathrm{~K}\right)$, achieving maximal heat rates of $1.25 \mathrm{~kW}$ (BC12). A similar behaviour can be observed by both concept designs when the results of the oil outlet temperature are shown (increase of the outlet temperature when the inlet mass flows increases too). The only exception happens when the mass flow is $0.1 \mathrm{~kg} / \mathrm{s}$, dropping the temperature slightly and increasing again with $0.2 \mathrm{~kg} / \mathrm{s}$. In case that the lowest outlet temperature must return to the heat source, only the lowest mass flow can fulfill this requirement.

The last analytical investigation dealt with the weighting ratios between the thermal resistances when the air heat transfer coefficient is modified, figure 11. 

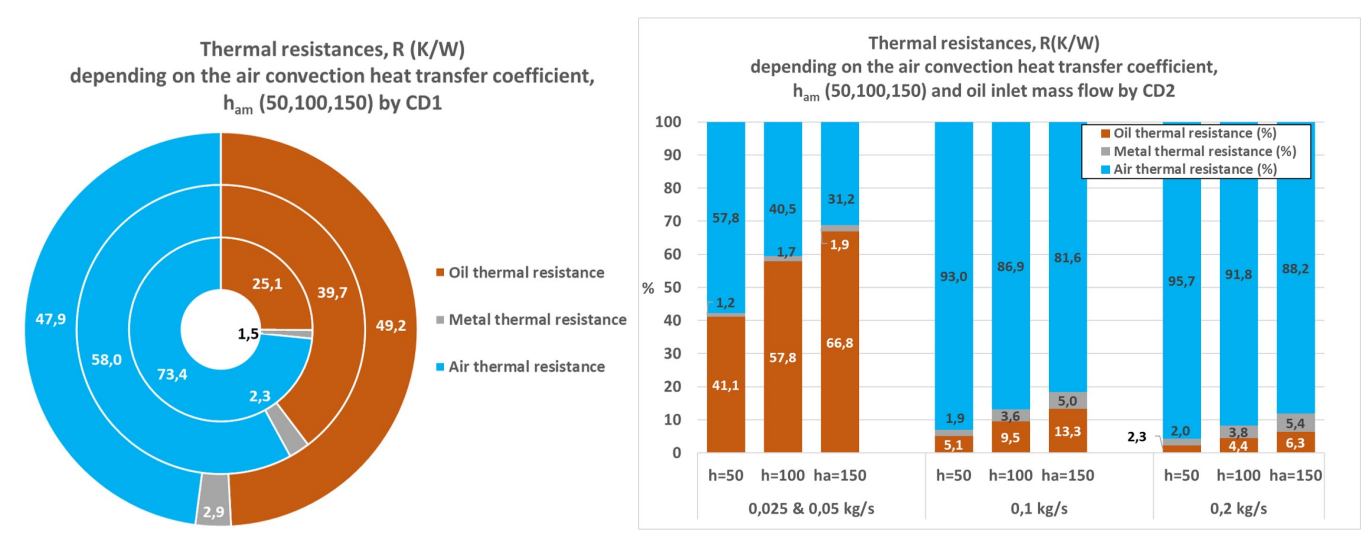

Figure 11. Influence of the air heat transfer coefficient on the dissipated heat rate (left) and on the outlet oil temperature (right) by the concept designs CD1 and CD2.

By CD1, the air thermal resistance predominates over the oil one by lower heat transfer coefficients, achieving a desired balance by $h_{m a}=150 \mathrm{~W} / \mathrm{m}^{2} \mathrm{~K}$ (air: $47.9 \%$; oil: $49.2 \%$ ). In the last case, the presence of bottlenecks in the heat dissipation are minimized. This is not the case by CD2, in which a balance between the air and oil thermal resistance is not achieved neither in the laminar nor in transition flows, being the weighting ratios by the transition case, around $90-10 \%$, much more unbalance as by the laminar one, $40-60 \%$.

\subsection{Pressure drop:}

The pressure drop in a hydraulic system can be defined as irreversible energy losses due to recirculation regions, separation and secondary flows and friction of the fluid with the walls. In a general form, and based on the relationship with the average kinetic pressure of the flow, the pressure drop definition of an hydraulic element, the Darcy-Weisbach equation (??eisbacheq:Darcy-Weisbachpends on geometrical dimensions of the oil cavity, length $L$ and hydraulic diameter of the cross section $D_{h}$, fluid properties, like the density $\rho$ and velocity $v$, and on the Darcy-friction factor $\lambda$, see equations (16)-(21):

$$
\Delta P=\lambda \frac{L}{D_{h}} \frac{\rho}{2} u^{2}
$$

The above equation is are valid only for straight pipes and do not take into account pressure losses due to change of the flow directions, like by bends. As by the 2 investigated concept designs are presented 180-degree bends, additional terms in the equation 22 are needed and assuming that an hydraulic system is composed by $N_{o}$ hydraulic elements (straight pipes, bends,...) a general expression of the pressure drop presents the following form [28]:

$$
\Delta P_{\text {total }}=\sum_{i=1}^{N_{o}}(\underbrace{\lambda \frac{L}{D_{h}} \frac{\rho}{2} u^{2}}_{\text {friction loss term }}+\underbrace{\zeta \frac{\rho}{2} u^{2}}_{\text {flow deflection loss term }})_{i}
$$


The second term, the flow deflection loss, presents a similar form as the friction loss term. The only difference is the addition of the curvature effects through the ratio $\frac{R}{D_{h}}=\frac{\text { radius of curvature }}{\text { hydraulic diameter }}$ and the correction factor [28]:

$$
\zeta_{\left(u, 90^{\circ}\right)}= \begin{cases}1.6 \lambda \sqrt{\frac{R}{d}} & \text { if } 8 \leq \frac{R}{d} \\ \lambda \frac{12.8}{\sqrt{\frac{R}{d}}} & \text { if } 2 \leq \frac{R}{d}<8 \\ \lambda \frac{12.8}{\sqrt{\frac{R}{d}}} \sqrt[4]{\frac{2}{\frac{R}{d}}} & \text { if } 1 \leq \frac{R}{d}<2\end{cases}
$$

where $\zeta_{u, 90}$ corresponds to the correction factor for $90^{\circ}$ bends. For $180^{\circ}$-bends, used in the 2 investigated concept designs, the correction factor can be derived using the expression $\zeta_{u, 180}=1.2 \zeta_{u, 90}$.

In picture 12 can be seen the analytical results of the pressure drop of both concept designs.
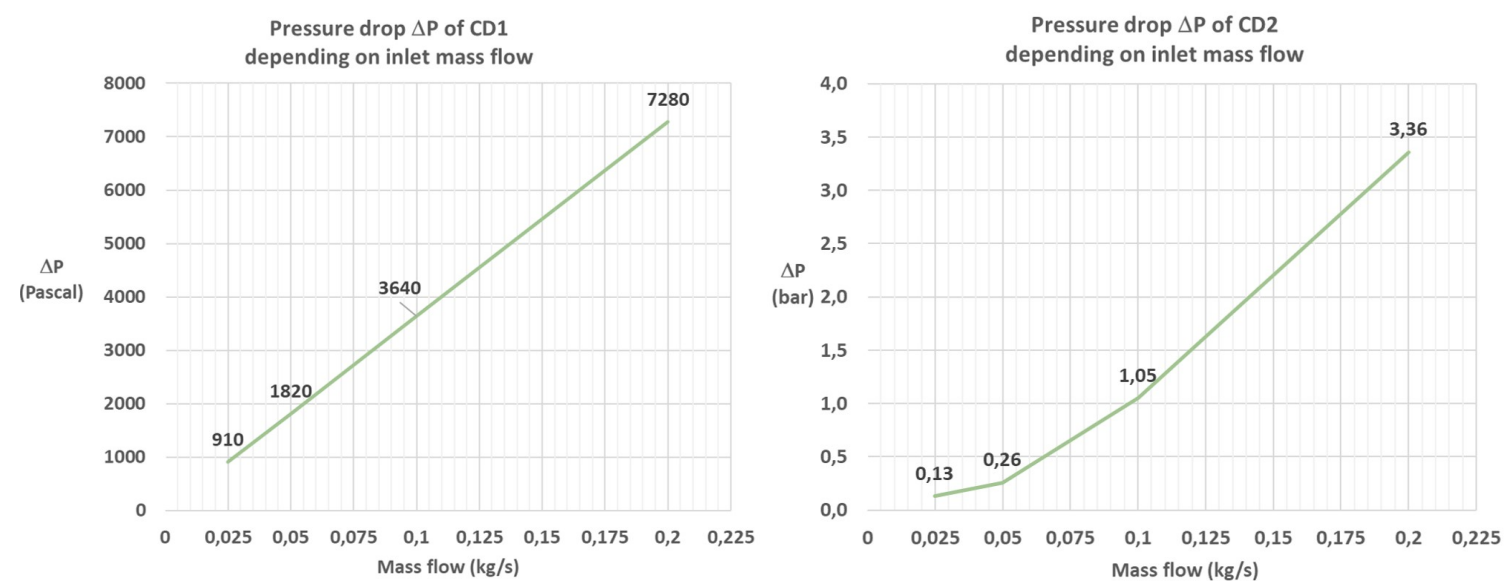

Figure 12. Pressure drop of CD1 and CD2.

By CD1 the pressure drop increases linearly due to the laminar nature of the flows (equations 21 and ??eisbacheq:Darcy-Weisbachmaining the maximal value below $8 \mathrm{kPa}$. Due to the cross section reduction by $C D 2$, the pressure drop is clearly higher than $C D 1$, achieving a peak of circa 3.4 bar by the maximal mass flow. A change of the flow behaviours (from laminar to transition) can be seen clearly when a mass flow of $0.1 \mathrm{~kg} / \mathrm{s}$ is achieved. Below this value the pressure drop presents a linear evolution whereas over it a quadratic dependency of the velocity can be observed.

\section{Numerical setup}

After the analytical calculations carried out in L3, the numerical setups used in the softwares Ansys Fluent ${ }^{\mathrm{TM}}$, Flownex ${ }^{\mathrm{TM}}$ and Ansys Mechanical ${ }^{\mathrm{TM}}$ for the simplification levels L0, L1 and L2 are explained.

\subsection{Ansys Fluent}

In our work the commercial software Ansys Fluent ${ }^{\mathrm{TM}} 2020 \mathrm{R} 2$ is employed for 3D steady-state conjugate heat transfer and computational fluid dynamic simulations of the FOGVC. As the influence in the results by using different simplification level (L0, L1 and L2) is investigated, different setups are needed to be defined. By all simulations, the Navier-Stokes equations (continuity, momentum and energy) for the laminar flows in the oil domain and the Reynolds-averaged Navier-Stokes equations (RANS) applying the $k-\omega$ SST turbulence model for oil and air domain in turbulent flows are employed.

By both concept designs a mesh study of the simulation domains oil and metal for the simplification level L2 has been carried out using 3 level of mesh refinements (coarse-C, fine-F, ultra fine-UF), table 4, to find a mesh which capture and model with enough precision the oil behaviour and the heat transmission without using unnecessary computational resources. 


\begin{tabular}{ccc}
\hline Mesh refinement & O-Oil Domain $\left[\cdot 10^{6}\right]$ & M-Metal Domain $\left[\cdot 10^{6}\right]$ \\
\hline C-Coarse & 5.3 & 3.6 \\
F-Fine & 10.4 & 4.9 \\
UF-Ultra fine & 19.8 & 7.6 \\
\hline
\end{tabular}

Table 4. Number of finite volume elements used in the mesh refinements of the mesh study for CD1 and CD2.

To model correctly the heat transfer mechanisms on the oil-metal-air interfaces, a refinement of the unstructured mesh including an inflation layer has been added. To avoid poor mesh quality elements, the coarsest refinement level has been established on a mesh with 5 millions control volumes on the oil domain. The fine and ultra fine refinement levels have been obtained doubling the immediately coarser level, respectively. A conformal mesh would be an option to model correctly the heat fluxes on the interface. The main disadvantage of this method is the unnecessary low size elements on the metal side. An alternative to this expensive method is a "quasi-conformal" mesh on which the mesh elements of the oil and metal domain do not coincide completely but an imposed growing mesh size factor, in our case of 1.75 , is used to delimit the size of the elements on the metal side of the interface, taking $(\text { mesh size })_{\text {metal }}=1.75 \cdot(\text { mesh size })_{\text {oil }}$.

To estimate the appropriate mesh refinement to be used in the simulations, a quantitative criterion, consisting of the comparison of pressure drop, outlet oil velocity, heat flow rate and oil outlet temperature in a steady state using the boundary condition $\mathrm{BC} 3$, have been employed, obtaining the following results, table 5 :

\begin{tabular}{l|ccc|c|ccccc}
\hline & \multicolumn{3}{c}{ CD-1 } & \multicolumn{3}{c}{ Differences } & CD-2 & \multicolumn{2}{c}{ Differences } \\
\hline Variables & C & F & UF & {$[\%]$} & C & F & UF & {$[\%]$} \\
\hline Pressure drop (Pa) & 3085 & 3113 & 3124 & 1.2 & 110127 & 109993 & 109681 & $<0.5$ \\
Outlet velocity (m/s) & 0.649 & 0.648 & 0.648 & $<0.1$ & 2.772 & 2.771 & 2.767 & 0.1 \\
\hline Lat. heat transfer (W) & -414.97 & -414.94 & -414.89 & $<0.1$ & -448.17 & -448.15 & -448.2 & $<0.1$ \\
Outlet temperature (K) & 371.2 & 371.2 & 371.2 & $<0.1$ & 371.1 & 371.1 & 371.0 & $<0.1$ \\
\hline
\end{tabular}

Table 5. Results of the mesh study of CD1 and CD2

By the comparison of the different variables using the 3 mesh refinement levels and observing that the differences of the studied variables are below $1.2 \%$ and $0.5 \%$ in CD1 and CD2, respectively, the coarsest mesh has been selected for the rest of the simulations. In L0 the mesh employed in the air domain is based on the application of a mesh size factor of 1.5 at the metal-air interface assuring good resolution of the boundary layer with a $y^{+}$in the range $0-8$, being a compromise between high accuracy and low computational times. The total size of the O-M-A meshes in L0 is of 68 and 65 millions of control volumes for CD1 and CD2, respectively. Some details of the meshes used in this work, mainly refinement zones and inflation layers, can be seen in picture 13.

For the CHT and CFD simulations, some assumptions have been taken: the oil behaves like an incompressible and Newtonian fluid and no phase change takes place (single phase). Moreover an inertial non-accelerating reference frame is used and both body forces (Coriolis, centrifugal and gravitational) and radiation heat transfer are negligible.

Depending on the simplification level, the simulated domains and the associated set-ups are different, picture 13. Starting with L2, only the oil domain $(\mathrm{O})$ is simulated substituting the metal domain by a shell conduction model, in which a constant thickness of $3 \mathrm{~mm}$ and a thermal conductivity value depending on the temperature is applied, and the air domain by a heat transfer coefficient and the air free stream temperature. At the oil inlet a constant mass flow and temperature boundary condition, see table 1 , with a turbulence intensity of $5 \%$ is employed while at the outlet the gauge pressure value is fixed. The no-slip condition is applied on the internal walls of the oil cavities. In L1 the setup for the oil domain is the same as by L2 but now the metal domain is simulated too and 


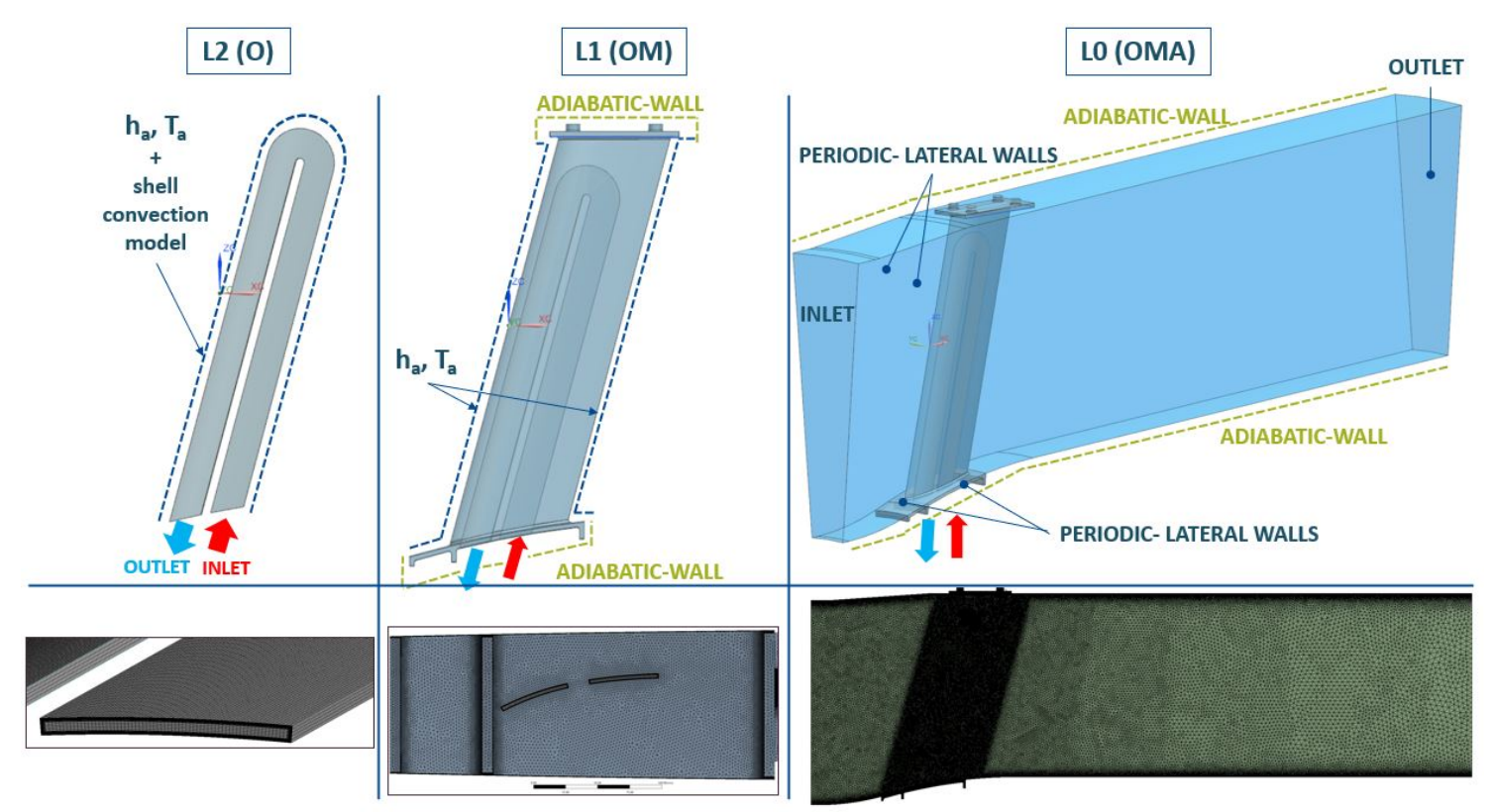

Figure 13. Different set-ups associated to the simplification levels L0, L1 and L2 (top) and mesh details (bottom) applied in this work by CD1.

not substituted by the shell conduction model. With the new configuration (O-M), on the surfaces in contact with the virtual air domain are applied again the same setup as by the L2 (an analytically calculated heat transfer coefficient and the air free stream temperature). On the remaining surfaces (platforms on the top and bottom of the FOGVC) is employed an adiabatic boundary condition due to the expected low temperature gradient and heat transfer coefficients between the FOGVC surfaces and the surroundings (nacelle and core engine). Moreover a periodic symmetry condition is needed on the lateral surface of the lower platform as only one sector is simulated. By the L0 no pre-assesed analytical calculations are needed to be applied on the external interfaces of the FOGVC, because the whole aero-thermo-fluid system (O-M-A) is simulated completely. The new boundary conditions to be defined are related with the air domain: adiabatic walls with no-slip condition on the top and bottom, a coupled metal-air interface, a periodic symmetry condition for the lateral surfaces and a pressure condition for inlet and outlet. The pressure condition at the inlet is composed of the application of a constant total pressure value of $102325 \mathrm{~Pa}$, a constant temperature of $50^{\circ} \mathrm{C}$ and the specification of the velocity components (tangential and axial) using the inlet total velocity value of $50 \mathrm{~m} / \mathrm{s}$ and the relative angle to the axial direction of $34^{\circ}$. As it is assumed that the flow after the fan does not contain the radial component, the associated angle is not needed. At the outlet is applied a constant pressure condition of $101325 \mathrm{~Pa}$.

Regarding the flow solver, the pressure-based one is employed in L0, L1 and L2 to cover the range of low Reynolds numbers of the incompressible oil flow side (laminar and turbulent) and turbulent subsonic flow on the air side. As Ansys Fluent ${ }^{\mathrm{TM}}$ is conceived on a monolithic way, only one flow solver resolves both fluid domains in L0, and although the nature of the flows are completely different, the solver is able to achieve the convergence by stabilizing the pressure-velocity coupling. That means that there are cases in which the $k-\omega$ SST model is applied in laminar oil flows provoking eventually lack of accuracy of the results. The effect of use turbulence models in laminar oil flows may be investigated on future works. Together with the decay of the residuals below a predefined threshold $\left(10^{-5}\right.$ in our research) of the continuity, velocity, energy and turbulent variables ( $k$ and $\left.\omega\right)$ additional convergence conditions have been applied, monitoring macroscopic variables in determined locations. For example, total temperature and pressure, mass flow and Reynolds number at the outlet and lateral heat transfer rate on the oil side, and the total mass flow on the air side have been monitored. Moreover the total heat transfer rate has been kept under surveillance. To be pointed out is that in some cases 
the convergence has been achieved when the monitored variables stabilized without oscillations over the residual threshold is achieved and vice versa (the stabilization of the monitored variables take place below the residual threshold). Following the recommendations of Ansys Fluent ${ }^{\mathrm{TM}}$ to improve the robustness, stability and convergence rate in the FOGVC ([27], [29]), the coupled pressure-velocity solver is selected, in which the governing equations of momentum and pressure-based are solved together, instead of the segregated one, like SIMPLEC or PISO. For the evaluation of the gradients, used in the discretization of the diffusive and convective term, the by default least-squares cell-based scheme is applied. Moreover interpolation schemes of second order for the pressure and second order upwind for the rest of variables (momentum, energy, turbulent kinetic energy and specific dissipation rate in turbulent flows) are used. To stabilize the solution two types of under-relaxation factors are available on the coupled pressure-based solver: the explicit one, in which the update of the variables is controlled in every iteration, and the implicit one, based on the under-relaxation of the discretized equations [29]. The default explicit factors (0.5) for momentum and pressure are used in this work. The implicit under-relaxation factor depends on the CFL number (Courant-Friedrichs-Lewy), taking the value 200 by default. In our work the stabilization of the solver is achieved using CFL values between 25 and 50, depending on the flow (laminar or turbulent) and the simplification level. To be pointed out is that the meaning of the CFL number used in this work is different to the CFL number defined in the convergence condition of explicit time-depending schemes. Before the simulations are started, hybrid initializations based on interpolation methods instead of the standard one, in which only constant values are selected, are carried out improving the initial values for the iterative solution process.

\subsection{Flownex}

Instead of modeling the aero-thermo-fluid system using a 3D software like Ansys FLUENT ${ }^{\mathrm{TM}}$, a 1D software at system and sub-system level, like Flownex ${ }^{\mathrm{TM}}$, can be employed to reduce the computational time at the expense of increase the simplification level, [30]. In Flownex the one dimensional governing equations of conservation of fluid dynamics are the basis for the numerical solutions of thermo-fluid networks. Flownex obtains values of mass flow/velocity, pressure and fluid temperature by solving the conservation equations of mass, momentum and energy using the Newton-Raphson method and implicit pressure correction solution algorithm, see [31] and [26]. There are three solvers in Flownex, each for pressure, flow and energy, using as convergence criterium for the residuals the value $1 \mathrm{e}-6$.

Applying the work methodology of Flownex to the investigated concept designs by L2, the figure 14 shows, how the different parts of the FOGVC have been simplified using 1D components.

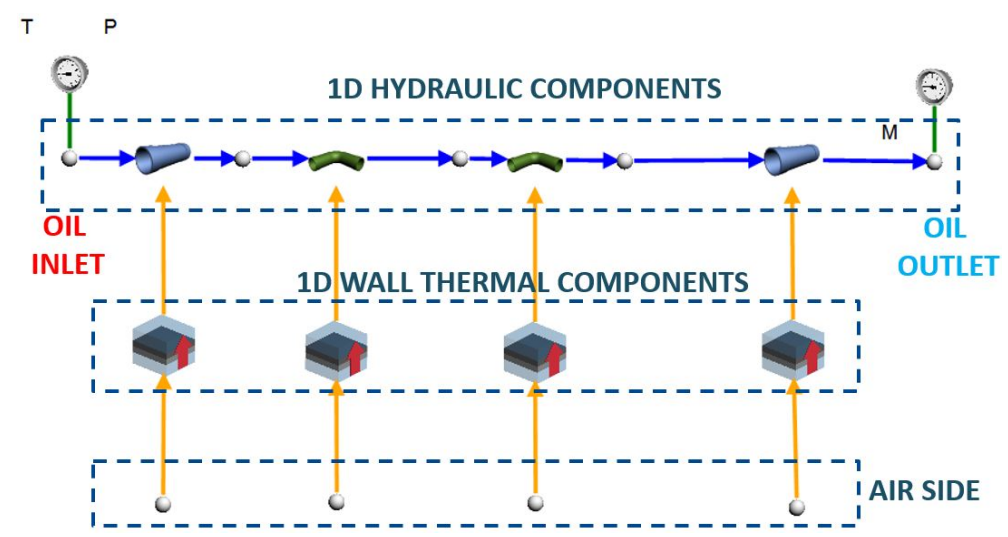

Figure 14. 1D Flownex diagram of the hydraulic, thermal and aero analysis of CD1 in simplification level L2. The diagram by CD2 is similar but having 22 hydraulic and thermal components (8 straight pipes $+1490^{\circ}$-bends). 
The metal domain is simplified to a pipe of certain thickness with oil domain in the internal side and air domain in the external. The air side convection is applied to outer area of the pipe. The input boundary condition required is the ambient air velocity, temperature and pressure. The hydraulic element on the setup is the pipe a flow component of oil domain, where the length, hydraulic diameter and the details of the loss factors from the oil circuit is defined. In Flownex the input boundary conditions of the oil domain such as input temperature and pressure are entered in the input $\mathrm{BC}$ node (T P) and the mass flow in $\mathrm{kg} / \mathrm{s}$ is provided in the output BC node (M). The component with red upward arrow marks is the composite heat transfer component, which acts thermal component of the oil domain. This calculates the average temperature and convection coefficient caused by the flow in the pipe element. The fluid material properties have been added in the form of tables depending on temperature. Regarding the bends and elbows, 2 different formulations are available: they are modeled using secondary losses with $\mathrm{k}$ factor or equivalent lengths or adding a component, as shown in figure 14. Primary frictional losses " $f$ " and the secondary losses "K" are integrated into momentum equation simulated in pipe the fluid flow component [32]. The pipe bend losses and pressure calculations on the oil side are also similar to the last section.

In thermal calculations, Flownex uses the Nusselt's correlation to calculate heat transfer coefficient from air side using the external cylinder forced convection model. In oil domain inside the tube Gnielinski's method is used for the convection transfer coefficient calculation. After calculating the convection transfer coefficients of both fluids the energy equation is solved numerically until convergence.

\subsection{Ansys Mechanical}

In this part of work a commercial software Ansys Mechanical ${ }^{\mathrm{TM}}$ the simplification level L1 is used for conjugate heat transfer and fluid dynamic simulations of FOGVC. ANSYS Mechanical ${ }^{\mathrm{TM}}$ is a simulation tool works on the principle of energy conservation and executed using Finite Element method. The heat balance equation is the basis for the thermal analysis obtained from the principle of energy conservation. [33]

The L1 geometric is further simplified by replacing the 3D oil body inside the circulating path with a 1D line element as shown in Figure 15 with an yellow highlight along the running length of the oil circuit. This 1D line has an attached cross section projecting along the length of the circulating path. This is achieved by assigning a uniform cross section to the 1D line body using the Design Modeller software in ANSYS Workbench ${ }^{\mathrm{TM}}[34]$.

geometry with $1 \mathrm{D}$ line.png

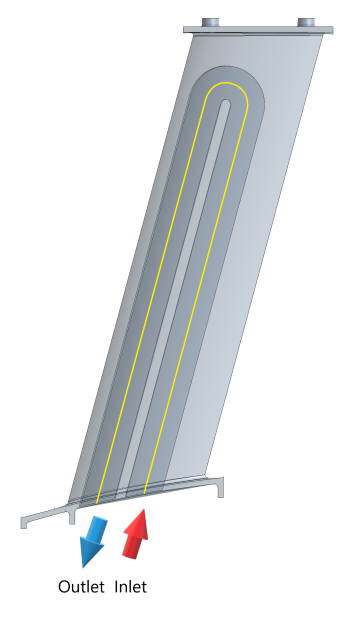

Figure 15. CD1 geometry in L1 simplification with 1D line at the center of Oil cavity 
The meshing is similar to the numerical setup in ANSYS Fluent ${ }^{\mathrm{TM}}$ in the case of metal domain and also in the oil-metal interface with an element size of $0.127 \mathrm{~mm}$. The only difference being in the oil domain mesh with edge sizing of $1 \mathrm{D}$ line body instead of 3D with element size $0.85 \mathrm{~mm}$. The area of the cross section of the oil domain combined with the element size projected as a single 3D element for representation purpose. In this study we are assuming steady-state thermal simulations with in-compressible fluid and non-linear material properties. ANSYS Mechanical ${ }^{\mathrm{TM}}$ contains variety of elements in its library applicable for structural, thermal, fluid, electric and magnetic analysis. The element type with suitable D.O.F decides the discipline of analysis. The library consists of one such suitable element known as FLUID 116 for simulation of fluid domain in this work. FLUID116 is an element with two primary nodes capable of conducting heat and transmitting fluid between its primary nodes ( $\mathrm{I}$ and $\mathrm{J}$ ) and hence is a suitable option for our simulation conditions. Additional two nodes can be added for convection if desired. The material properties required are as follows, conductivity $=$ KXX, density $=$ DENS, coefficient of friction $=$ MU , fluid viscosity $=$ VISC and Specific heat $=$ C. For convection analysis following are the input parameters: $\mathrm{D}=$ hydraulic diameter and $\mathrm{F}=$ nodal heat or fluid flow rate in units mass/time. In this case the film coefficient data is stored and is used by surface elements SURF 152. The SOLID87 is a 10 node, 3D tetrahedral solid thermal element used in metal domain and is very well suited for CAD/ CAM system geometries consisting of unstructured mesh similar to our case [34].

The element programming in ANSYS Mechanical ${ }^{\mathrm{TM}}$ of FLUID116 does not support the calculation of fluid temperature, solid temperature and pressure loss calculation simultaneously. Hence, there is a need to perform two different simulation one to understand the thermal behaviour of solid with fluid and another for pressure loss in fluid.

The Steady State thermal simulation consists of air to metal convection, metal to oil convection, temperature changes in oil and metal domains. The boundary conditions assigned to the metal surfaces on air side for convection is similar to L1 in ANSYS Fluent ${ }^{\mathrm{TM}}$ setup. Oil-metal convection coefficient is applied to the circuit walls and the temperature is taken from each 1D elements of fluid flow at corresponding locations. Mass flow for on the 1D-oil line is applied in $\mathrm{kg} / \mathrm{s}$ and fluid temperature at the first element of the inlet side. Thermal fluid is selected as model type in geometry and Fluid 116 is assigned as element for the simulation [35]. The heat convergence value reference is at 1e-5. In simulation results we have the following points of interests: Outlet temperature of the oil, temperature distribution on the surface of the metal and heat transfer between oil and metal as a result of convection.

The pressure simulation is also carried out in the Steady State Thermal component of the ANSYS workbench ${ }^{\mathrm{TM}}$ ANSYS Mechanical ${ }^{\mathrm{TM}}$. Initial temperature is provided as in Steady State Thermal analysis. The commands under the geometry tree help to change the analysis type from thermal to fluid by switching to the pressure DOF of element FLUID116. Then the details like hydraulic diameter and friction factor are added for each segment of straight line and bends. Further, commands applied under steady state thermal tree defines the boundary conditions like mass flow and initial pressure. Finally, Commands are used to define the time steps which is basically iterations in steady state analysis since APDL works as a quasi-static type analysis [33]. The point of interest in this simulation are Reynolds's number, fluid flow velocity in $\mathrm{m} / \mathrm{s}$ and pressure difference between inlet and outlet of the oil circuit.

\section{Numerical Results and Discussion}

In this section some comparison of the numerical and analytical results belonging to the different simplifications levels are presented. 3 variables are mainly investigated and compared: the oil outlet temperature, the dissipated heat rate from the oil to the air side and the pressure drop of the oil side. Another variables related with the 3 above are depicted, like the heat transfer coefficients on the oil-metal and metal-air interfaces, to understand better the influence of the used methodology.

The first results, figure 16 and 17, show the evolution of the outlet oil temperature depending on the inlet mass flow, the employed software and the air heat transfer coefficient (only by L0, L1 and L2). 
Moreover are depicted the differences of the results fixing the heat transfer coefficient on the air side on $150 \mathrm{~W} / \mathrm{m}^{2} \mathrm{~K}$ and taking the $\mathrm{L} 0$ as the reference method.
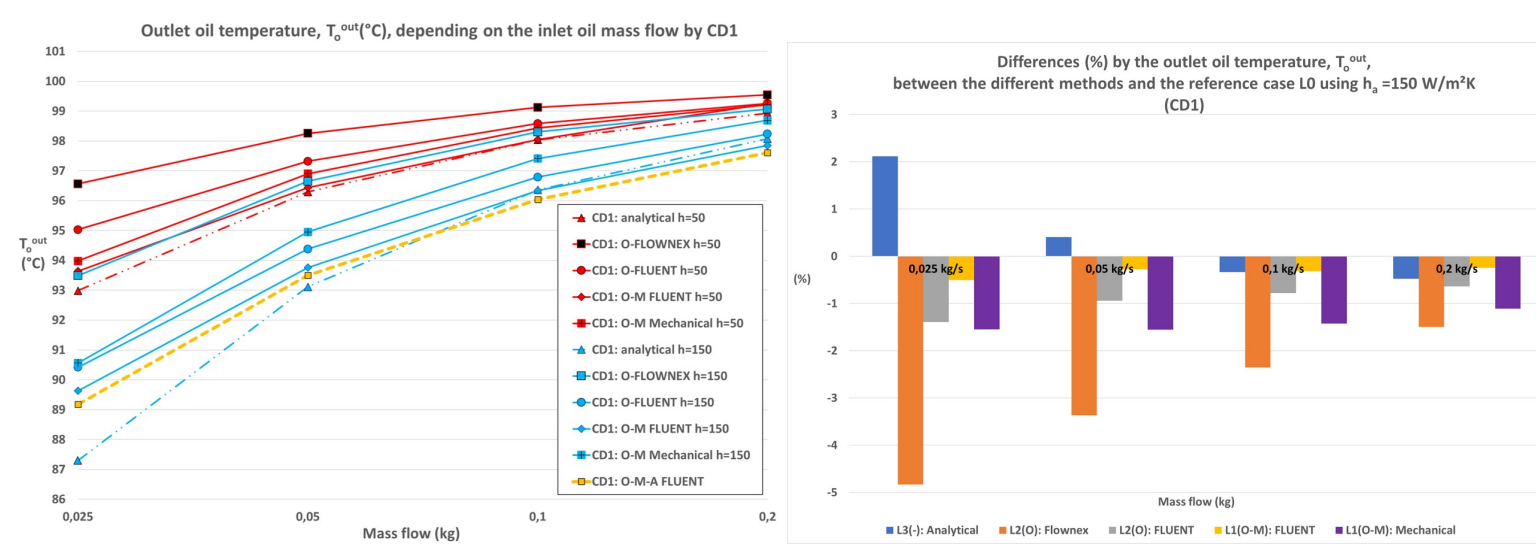

Figure 16. Comparison of the oil outlet temperature results (left: absolute values, right: deviations respected to the L0 level) between the different simplification levels in CD1.

By CD1, the oil outlet temperature increases continuously by increasing the inlet mass flow, being framed on the range $86-100^{\circ} \mathrm{C}$. On the contrary, the differences with the reference level L0 decrease by all employed softwares, having a maximal difference of $5 \%$, when Flownex is used. The same tendency is observed by $C D 2$, figure 17, obtaining a maximal deviation of circa 9\% (Ansys Mechanical), by the lowest mass flow. With some exceptions (in CD1 the two lowest mass flows and in CD2 the two highest flows with transition/turbulent behaviour) are the results of $\mathrm{L} 0$ overestimated by the other methods being the results using $h_{a}=150$ more accurate (closer to L0) than the results of $h_{a}=50$. In CD2, the change from laminar to transition/turbulent flows has a clear impact on the outlet temperature provoking a slight descend (from 0.5 to $0.1 \mathrm{~kg} / \mathrm{s}$ ). No large deviations are expected by the outlet temperature due to the small range of temperatures obtained.
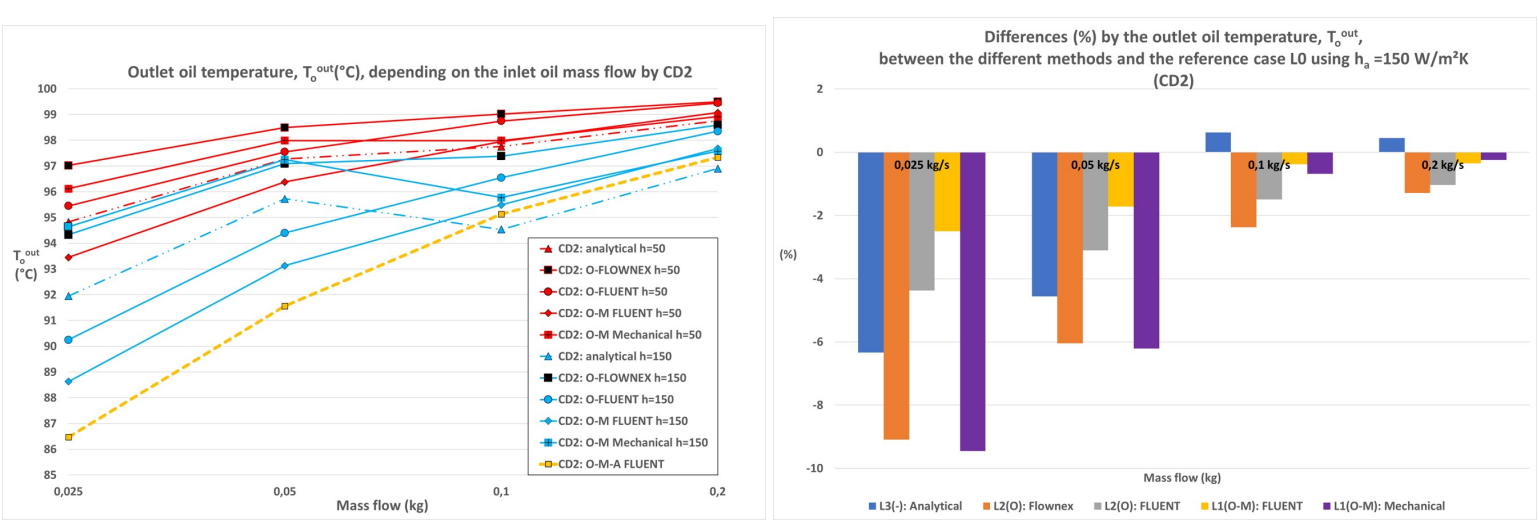

Figure 17. Comparison of the oil outlet temperature results (left: absolute values, right: deviations respected to the L0 level) between the different simplification levels in CD2.

The results of dissipated heat are now depicted, figures 18 and 19. In CD1 and CD2, the values of the different methods underestimate the results of L0 with some exceptions (CD1: lowest mass flows. $\mathrm{CD} 2$ : turbulent flows). Moreover the same tendency (the higher mass flows, the higher the dissipated heat) is observed. 

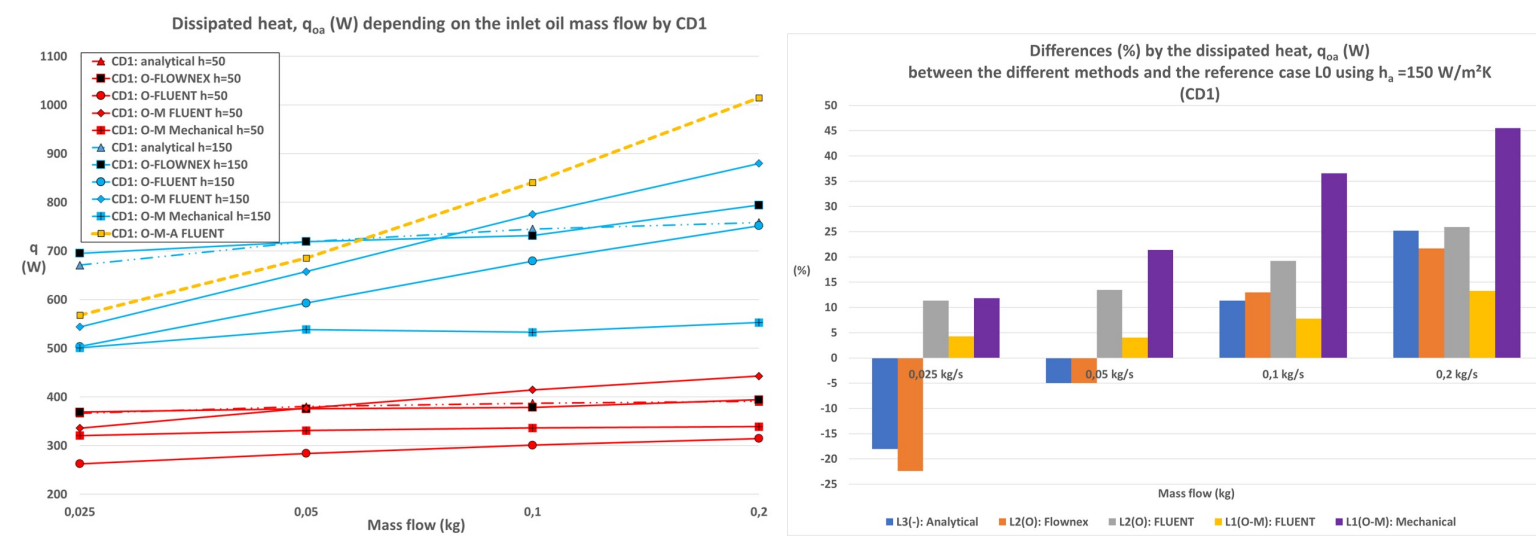

Figure 18. Comparison of the dissipated heat results (left: absolute values, right: deviations respected to the L0 level) between the different simplification levels in CD1.

Regarding the differences with the reference level, it can be seen in CD1 that they increase with the exception of the lowest mass flow. To be added is that the deviations are more larger than by the outlet temperature (until 45\% can be achieved using Ansys Mechanical with the highest mass flow). Comparing the different softwares, Ansys Fluent (L1-O-M) obtains the closest results to L0 presenting maximal deviations of circa $15 \%$.

The results in CD2 repeat the previously mentioned behaviour by augmenting the mass flows achieving maximal values of over $65 \%$ (Ansys Mechanical by $0.1 \mathrm{~kg} / \mathrm{s}$ ). A clear increment of dissipated heat takes place by mass flows of $0.1 \mathrm{~kg} / \mathrm{s}$ but at the same time the deviations are reduced considerably.
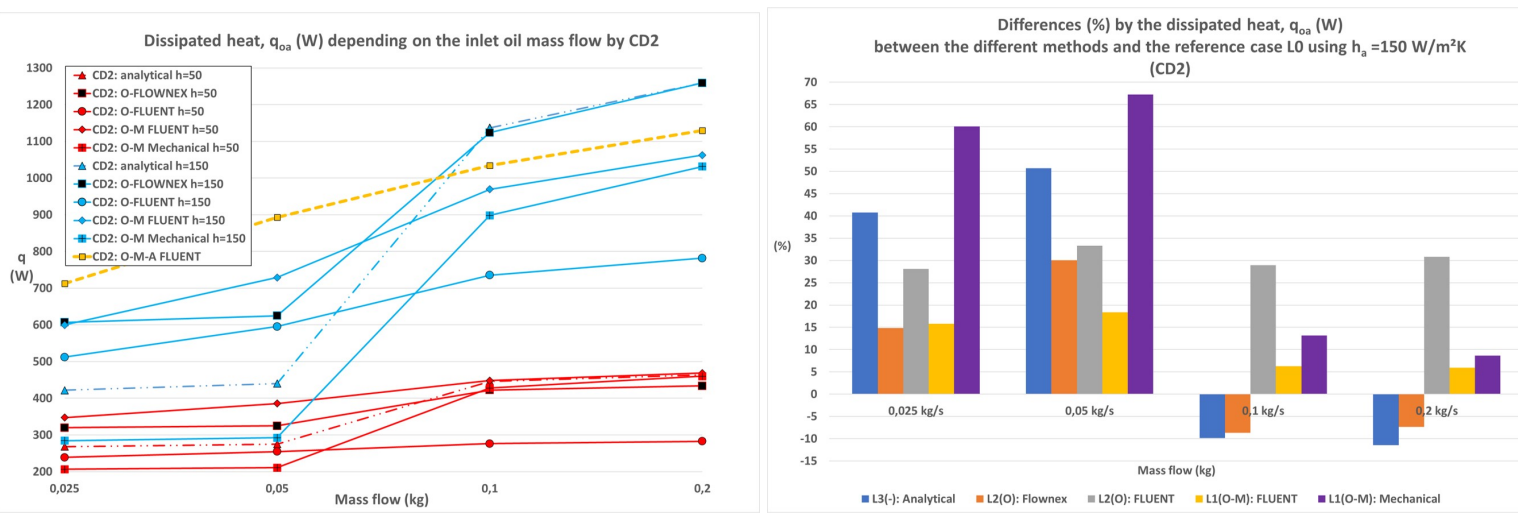

Figure 19. Comparison of the dissipated heat results (left: absolute values, right: deviations respected to the L0 level) between the different simplification levels in CD2.

The pressure drop is the last variable to be commented, figure 20 and 21. As expected, in CD1 a linear behaviour of the pressure drop in the whole laminar range can be seen, when a method is used, which is based on analytical equations. By the numerical methods, mainly 3D CFD, this behaviour changes to quasi-linear or even parabolic. This evolution becomes clear in CD2 when the mass flows achieves transition-to-turbulent structures. While the pressure drop in CD1 remains in very low values (under $10000 \mathrm{~Pa}$ ), the pressure range of CD2 varies strongly with the increment of the mass flow achieving values near to 4 bar. As explained before, the main reason is, although both concept designs present a similar hydraulic diameter, the lower cross section of CD2, which provokes higher velocities and hence pressure losses. Moreover the high number of bends contributes negatively. Examining the deviations related to the reference level, L0, in CD1, Flownex and the analytical method present the maximum values ( $50 \%$ and $25 \%$, respectively). In case of Flownex, the main reason for that is the correction of the cross section applied in the bend. In CD2, the maximal deviations appear mainly by laminar flows, decreasing strongly when the transition-to-turbulent flow are predominant. 

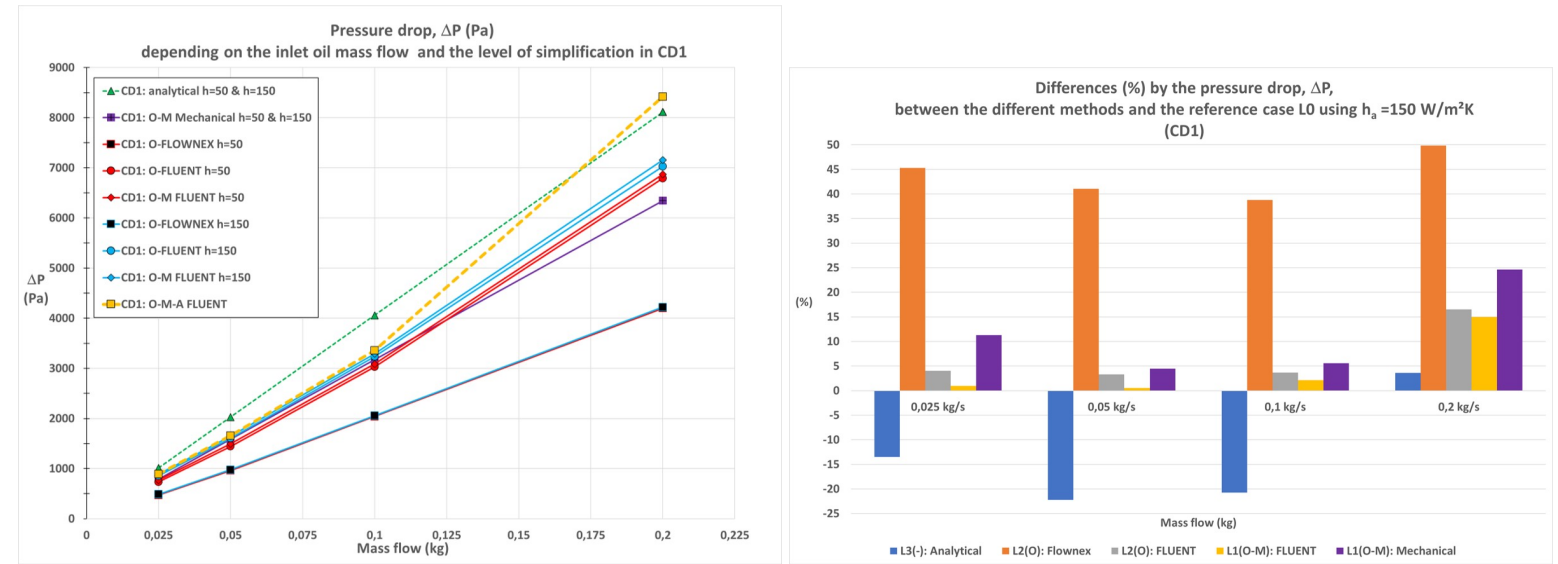

Figure 20. Comparison of the pressure drop results (left: absolute values, right: deviations respected to the L0 level) between the different simplification levels in CD1.
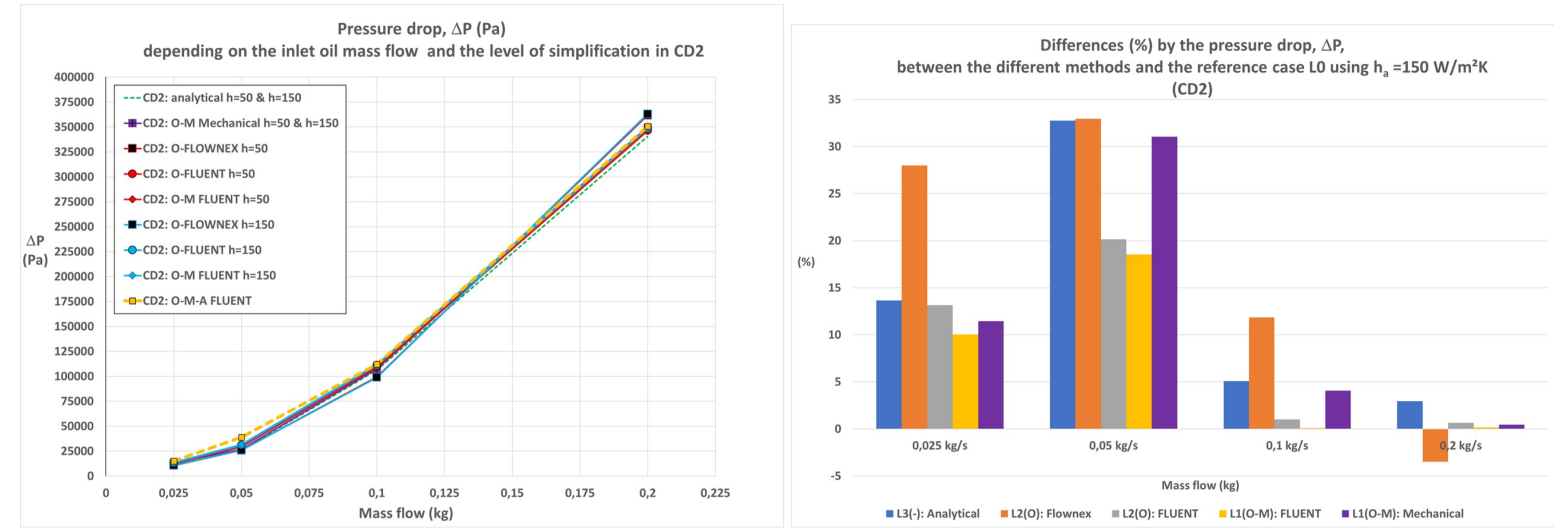

Figure 21. Comparison of the pressure drop results (left: absolute values, right: deviations respected to the L0 level) between the different simplification levels in CD2.

After the quantitative result comparison depicted in the last figures, a qualitative comparison is presented in the following figures, 22 and 23. The figure 22 represents the temperature distribution of L0 in CD1 for the predefined boundary conditions (BC1-L0, BC2-L0, BC3-L0 and BC4-L0). 


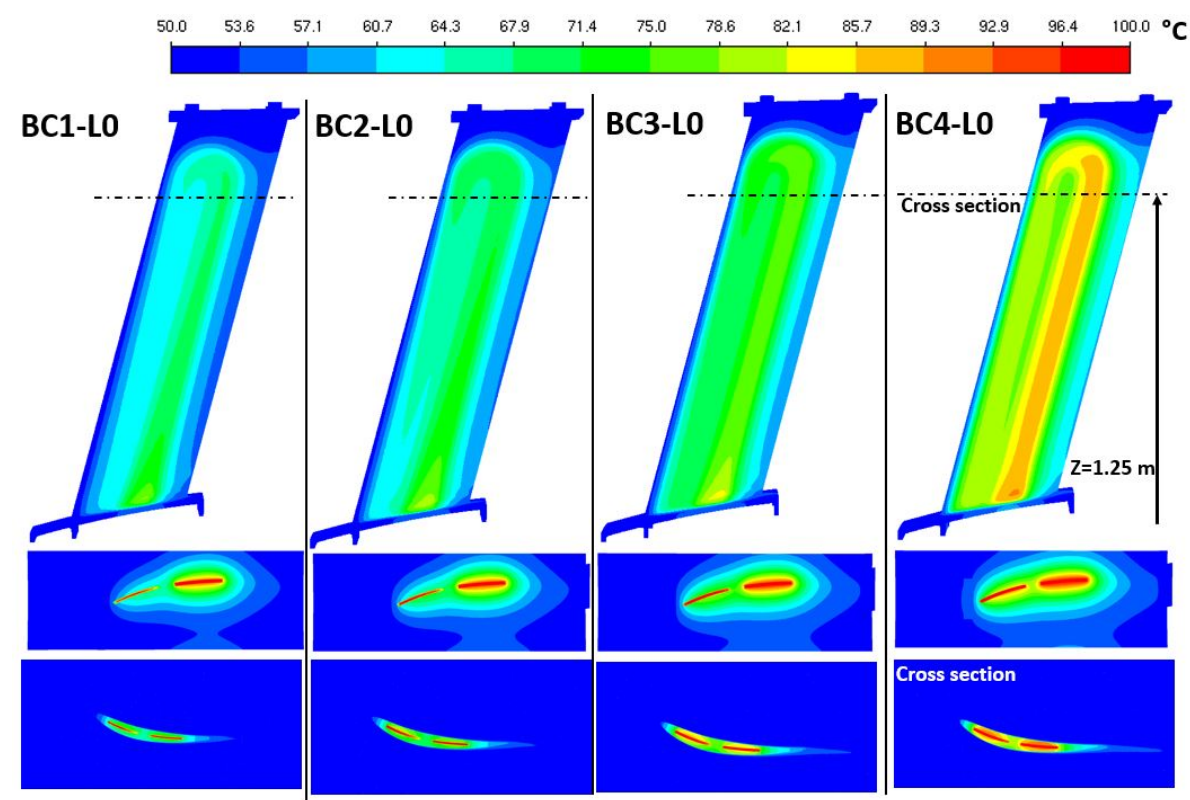

Figure 22. Temperature distribution of L0 in CD1 for the predefined boundary conditions (BC1-L0, $\mathrm{BC} 2-\mathrm{L} 0, \mathrm{BC} 3-\mathrm{L} 0$ and BC4-L0). The pictures on the top, middle and bottom are created using the positive tangential direction, the positive radial direction (detail of the oil inlet and outlet) and an axial cross section at $\mathrm{z}=1.25 \mathrm{~m}$, respectively.

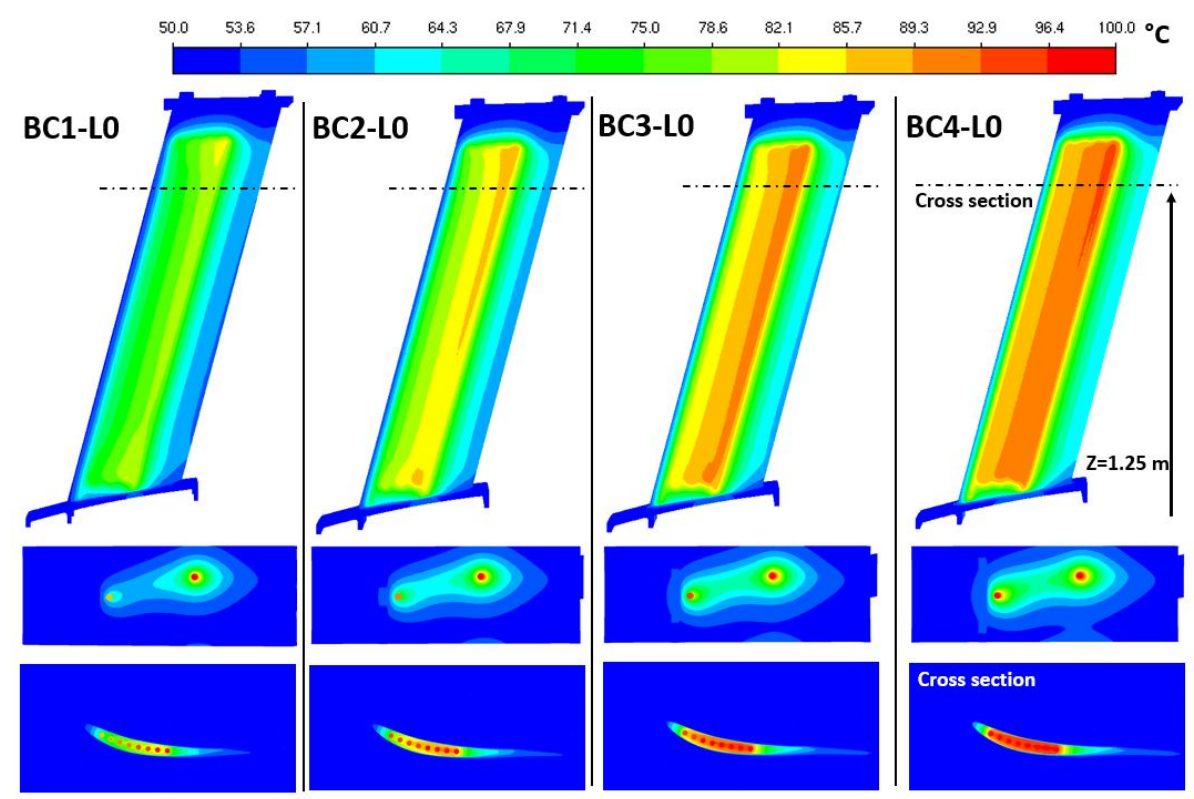

Figure 23. Temperature distribution of L0 in CD2 for the predefined boundary conditions (BC1-L0, $\mathrm{BC} 2-\mathrm{L} 0, \mathrm{BC} 3-\mathrm{L} 0$ and BC4-L0). The pictures on the top, middle and bottom are created using the positive tangential direction, the positive radial direction (detail of the oil inlet and outlet) and an axial cross section at $\mathrm{z}=1.25 \mathrm{~m}$, respectively.

\section{Conclusions}

In this work 0D-1D-3D and fully 3D steady-state aero-thermo-fluid simulations of a structural oil-to-air Fan Outlet Guide Vane Cooler (FOGVC) in a jet engine are presented. Using the commercial softwares Ansys Fluent ${ }^{\mathrm{TM}}$, the thermo-mechanical module of Ansys ${ }^{\mathrm{TM}}$ and the $1 \mathrm{D}$ fluid solver Flownex $^{\mathrm{TM}}, 5$ simulation types (3D fully conjugate heat transfer with and without a thin wall model, 3D with a thin wall model, 1D-3D coupled, 1D and OD) corresponding to 4 levels of simplification 
in 3 possible domains (oil, oil-metal and oil-metal-air) have been compared to provide a selection criteria when a determined level of accuracy in the simulations without prohibited computational times is desired. The methodologies are applied to two different oil internal cavities: an inverted $U$ with rectangular cross section and a coil internal cavity with a circular cross section.

The obtained results show that depending on the scope of the research, one method or the other may be used. If an accurate outlet oil temperature is needed, the analytical methods L3 and L2 (O) Flownex method are completely recommended due to the very low computational time (some seconds). That is not the case when the pressure drop should be assessed. The above two methods can be employed but foreseeing possible huge deviations. A compromise may be the L2(O) Ansys Fluent method. In case that the dissipated heat is the key variable to be investigated, an adequate and accurate alternative would be the L1 (O-M) Ansys Fluent method. The L0 is only recommended when the effect of the air side should be investigated due to the high computational costs. If the thermal distribution within the FOGVC (metal domain) is needed, there are only 2 options available: L1 (O-M) Fluent or L2(O) Mechanical. For a first estimation, the second method is recommended but assuming lower accuracy by the results. Experimental data would be needed to validate the numerical results by all employed methodologies and geometries.

Author Contributions: Conceptualization: L.C.S; methodology: L.C.S; simulations FLOWNEX and ANSYS APDL: S.S.B.; Ansys Fluent: L.C.S.; meshing: L.C.S. and S.S.B.; investigation: L.C.S. and S.S.B.; writing-original draft preparation: L.C.S. and S.S.B.; writing-review and editing: K.H.; visualization: L.C.S. and S.S.B.; supervision: L.C.S.; project administration: K.H.; funding acquisition: K.H.

All authors have read and agreed to the published version of the manuscript.

Funding: The APC has received funding from the European Union's Horizon 2020 research and innovation program under grant agreement No 690808 (project Surface Heat Exchanger for Aero Engines 2 - SHEFAE2).

Acknowledgments: The authors of this work are very grateful to Zahid Hussain (Rolls Royce plc.) for the review and comments of this work and to associate professor Fernando Varas Mérida (ETSIAE-UPM) for his support by the numerical simulations.

Conflicts of Interest: The authors declare no conflict of interest. The founding sponsors had no role in the design of the study; in the collection, analyses, or interpretation of data; in the writing of the manuscript, and in the decision to publish the results.

\section{Abbreviations}

The following abbreviations are used in this manuscript: 


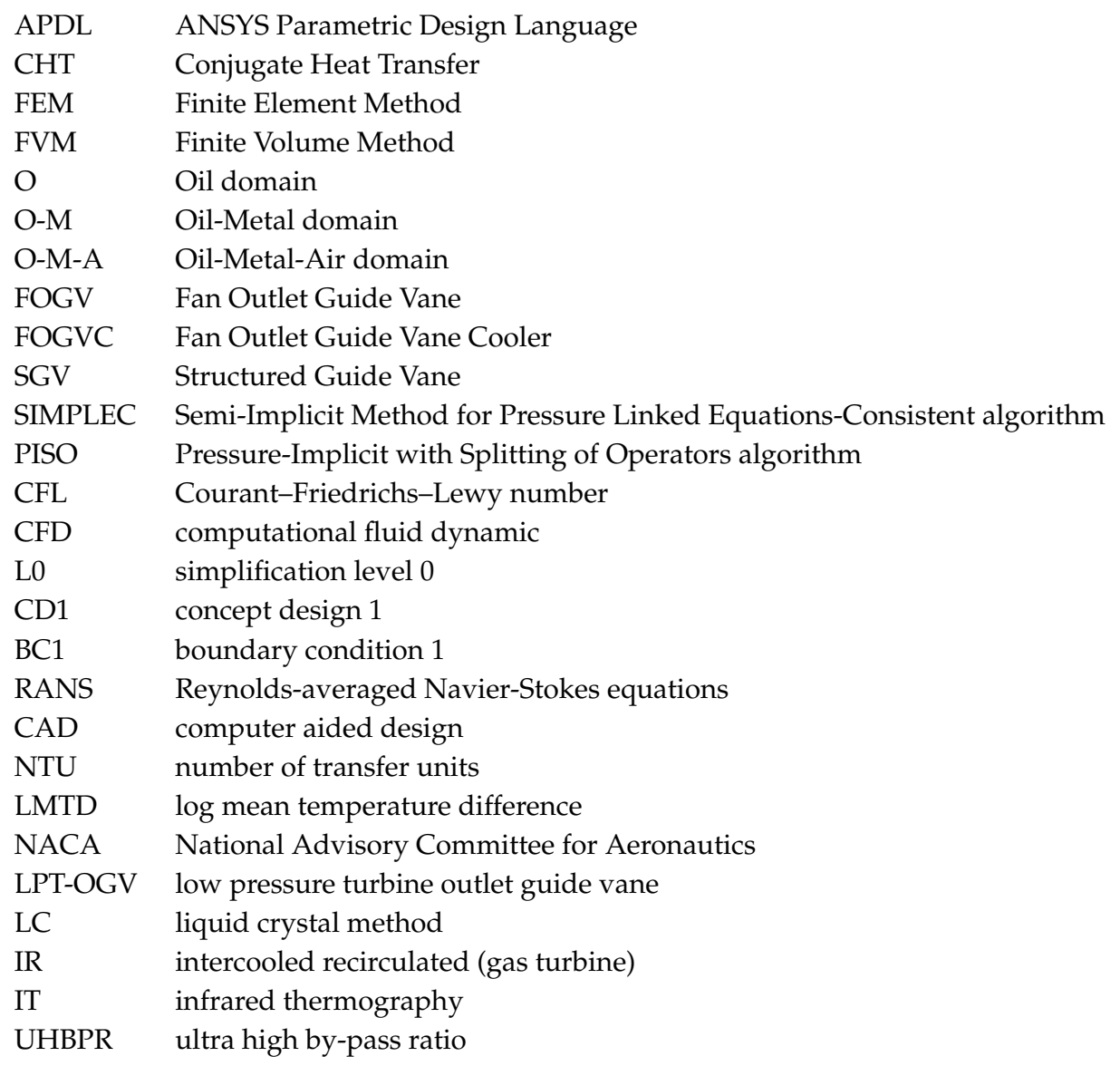

\section{References}

1. Commission., E. 2030 Climate Target Plan., 2020, https:/ / ec.europa.eu/clima/policies/eu-climate-action/ 2030_ctp_en, accessed on 2021-03-03.

2. Royce., R. Future of flight., https://www.rolls-royce.com/media/our-stories/innovation/2016/advanceand-ultrafan.aspx, accessed on 2021-06-02.

3. Commission., E. Horizon 2020., https://ec.europa.eu/programmes/horizon2020/en, accessed on 2021-05-25.

4. Commission., E. Horizon Europe., https://ec.europa.eu/info/research-and-innovation/funding/fundingopportunities/funding-programmes-and-open-calls/horizon-europe_en, accessed on 2021-05-25.

5. Royce., R. UltraFan. The Ultimate TurboFan., https://www.rolls-royce.com/ /media/Files/R/ Rolls-Royce/documents/civil-aerospace-downloads/High-Res-posters/high_res_ultrafan.pdf, accessed on 2021-03-03.

6. VENKATARAMANI, K.S.; MONIZ, T.O.; STEPHENSON, J.P. Heat transfer system and method for turbine engine using heat pipes. EP EP1884625A2, 02, 2008.

7. WOOD, T.H.; WETZEL, T.G.; LUEDKE, J.G.; TUCKER, T.M. Combined acoustic absorber and heat exchanging outlet guide vanes. US US8333552B2, 12, 2012.

8. KNIGHT III, G.; LUKOVIC, B.; LABORIE, D.; SCHEFFEL, K.S. Gas turbine engine airfoil integrated heat exchanger. US US8616834B2, 12, 2013.

9. GERSTLER, W.D.; KOSTKA, J.M.; RAMBO, J.D.; MOORES, J.W. Gas turbine engine component with integrated heat pipe. EP EP3081755A1, 10, 2016.

10. SNYDER, D.J. Fluid cooling system integrated with outlet guide vane. US US20170292531A1, 10, 2017.

11. CHALAUD, S.; VESSOT, C. Turbomachine provided with a vane sector and a cooling circuit. US US20180087392A1, 03, 2018. 
12. ZACCARDI, C.; BOUTALEB, M.L.; CHALAUD, S.C.; LEMARECHAL, E.P.G.; PAPIN, T.G.P. Output director vane for an aircraft turbine engine, with an improved lubricant cooling function using a heat conduction matrix housed in an inner duct of the vane. US US10392952B2, 08, 2019.

13. SENNOUN, M.E.H. OGV heat exchangers networked in parallel and serial flow. US US10196932B2, 02, 2019.

14. Wang, L.; Sundén, B.; Chernoray, V.; Abrahamsson, H. Endwall Heat Transfer Measurements of an Outlet Guide Vane at On and Off Design Conditions. Volume 3C: Heat Transfer; American Society of Mechanical Engineers: San Antonio, Texas, USA, 2013; p. V03CT14A017. doi:10.1115/GT2013-95008.

15. Wang, C.; Wang, L.; Sundén, B.; Chernoray, V.; Abrahamsson, H. An Experimental Study of Heat Transfer on an Outlet Guide Vane. Volume 5B: Heat Transfer; American Society of Mechanical Engineers: Düsseldorf, Germany, 2014; p. V05BT14A001. doi:10.1115/GT2014-25100.

16. Wang, C.; Luo, L.; Wang, L.; Sundén, B.; Chernoray, V.; Arroyo, C.; Abrahamsson, H. Experimental and numerical investigation of outlet guide vane and endwall heat transfer with various inlet flow angles. International Journal of Heat and Mass Transfer 2016, 95, 355-367. doi:10.1016/j.ijheatmasstransfer.2015.11.029.

17. Rojo Perez, B.M. Aerothermal Experimental Investigation of LPT-OGVs. PhD Thesis, Chalmers University of Technology, Gothenburg, Sweden, 2017.

18. Jonsson, I.; Chernoray, V.; Dhanasegaran, R. Infrared Thermography Investigation of Heat Transfer on Outlet Guide Vanes in a Turbine Rear Structure. International Journal of Turbomachinery, Propulsion and Power 2020, 5, 23. doi:10.3390/ijtpp5030023.

19. Ito, Y.; Inokura, N.; Nagasaki, T. Conjugate Heat Transfer in Air-to-Refrigerant Airfoil Heat Exchangers. Journal of Heat Transfer 2014, 136, 081703. doi:10.1115/1.4027554.

20. Ito, Y.; Nakanishi, H.; Fukazawa, K.; Nagasaki, T. Geometric effect on heat transfer of airfoil heat exchanger. Asian Congress on Gas Turbines ACGT2016; , 2016; p. 9.

21. Raatikainen, R.; Nousiainen, R.; Österberg, K.; Riddone, G.; Samochkine, A.; Gudkov, D. Applying one-dimensional fluid thermal elements into a 3D clic accelerating structure. CERN Open; CERN (European Organization for Nuclear Research): Geneva, 2010; Vol. 032, p. 7.

22. van Antwerpen, H.J.; Mulder, E.J. A Technique to Simulate a Tube Break in a High-Pressure Gas/Cooling Water Heat Exchanger. Fourth International Topical Meeting on High Temperature Reactor Technology, Volume 1; ASMEDC: Washington, DC, USA, 2008; pp. 667-675. doi:10.1115/HTR2008-58161.

23. Nouri, B.; Kuhhorn, A. Automated CAE process for thermo-mechanical lifing prediction of a parameterized turbine blade with internal cooling. 1th World Congress on Computational Mechanics (WCCM XI) 5th European Conference on Computational Mechanics (ECCM V) 6th European Conference on Computational Fluid Dynamics (ECFD V; , 2014; p. 16.

24. Airfoil Tools, 2021, http:/ / airfoiltools.com/, accessed on 2021-04-16.

25. Incropera, F.P.; DeWitt, D.P.; Bergman, T.L.; Lavine, A.S., Eds. Fundamentals of heat and mass transfer, 7. ed., ed.; John Wiley \& Sons, Ltd: Hoboken, NJ, 2011. OCLC: 62532755.

26. Flownex. Flownex Library Manual. Version 8.10. 2019.

27. Baker, T.J. Ansys Fluent User's Guide 2020R2. 2020.

28. Wagner, W. Strömung und Druckverlust: mit Beispielsammlung, 5 ed.; Vogel: Würzburg, 2001.

29. Abrahamson, J. Ansys Fluent Theory Guide 2020R2. 2020.

30. Flownex® SE. TUTORIAL 6 - Heat Exchanger, 2019.

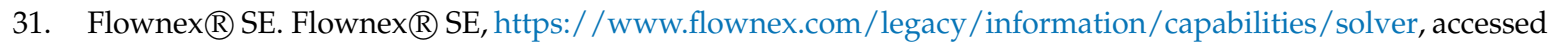
on 2019. Flownex $($ SE.

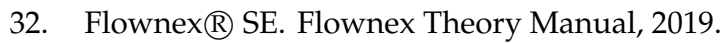

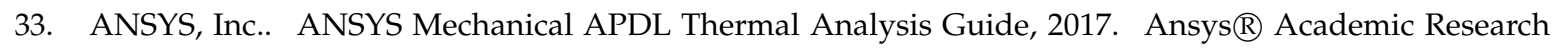
Mechanical, Release 18.1, Help System, Steady-state thermal analysis, ANSYS, Inc.

34. ANSYS, Inc.. ANSYS Mechanical APDL Element Reference, 2013. Ansys $®$ Academic Research Mechanical, Release 15.0, Help System, Coupled Thermal-Fluid Pipe, ANSYS, Inc.

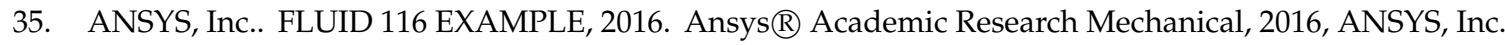

Sample Availability: Samples of the compounds ...... are available from the authors. 